\title{
Key signalling factors and pathways in the molecular determination of skeletal muscle phenotype
}

\author{
K.C. Chang ${ }^{\dagger}$ \\ Molecular Medicine Laboratory, Division of Animal Production and Public Health, University of Glasgow Veterinary School, Bearsden Road, Glasgow G61 1QH, UK
}

(Received 7 September 2006; Accepted 16 January 2007)

\begin{abstract}
The molecular basis and control of the biochemical and biophysical properties of skeletal muscle, regarded as muscle phenotype, are examined in terms of fibre number, fibre size and fibre types. A host of external factors or stimuli, such as ligand binding and contractile activity, are transduced in muscle into signalling pathways that lead to protein modifications and changes in gene expression which ultimately result in the establishment of the specified phenotype. In skeletal muscle, the key signalling cascades include the Ras-extracellular signal regulated kinase-mitogen activated protein kinase (Erk-MAPK), the phosphatidylinositol 3'kinase (PISK)-Akt1, p38 MAPK, and calcineurin pathways. The molecular effects of external factors on these pathways revealed complex interactions and functional overlap. A major challenge in the manipulation of muscle of farm animals lies in the identification of regulatory and target genes that could effect defined and desirable changes in muscle quality and quantity. To this end, recent advances in functional genomics that involve the use of micro-array technology and proteomics are increasingly breaking new ground in furthering our understanding of the molecular determinants of muscle phenotype.
\end{abstract}

Keywords: hyperplasia, hypertrophy, meat quality, muscle fibres, skeletal muscle

\section{Introduction}

\section{Importance of muscle fibre phenotype}

The key constituents of muscle are muscle fibres, and their associated extracellular matrix in which are located the vascular supply, collagenous component and adipose tissue (intramuscular fat) of muscle. Muscle phenotype conferred by fibres is central to the quantity and quality of meat production. Quantity is the outcome of muscle fibre hyperplasia and hypertrophy. Hyperplastic growth in utero is primarily dependent on myocyte proliferation and differentiation (Oka et al., 2002). Post-natal growth is mainly the result of hypertrophy or enlargement of existing and replaced muscle fibres. Quality is a more complex trait and is assessed by a variety of objective and subjective measurements, such as colour, $\mathrm{pH}$, tenderness, odour and juiciness. It is well established that fibre type composition is a key determinant of both meat quantity and quality. In the pig, in particular, favourable meat traits such as tenderness and colour, have been found to closely associate with the greater abundance of oxidative fibres (Klont et al., 1998; Karlsson et al., 1999; Chang et al., 2003; Maltin et al., 2003; Wood et al., 2004). Red or highly oxidative

\footnotetext{
${ }^{\dagger}$ E-mail: k.chang@vet.gla.ac.uk
}

muscles possess higher lipid concentration which is associated with more tender meat (Hocquette et al., 1998; Wood et al., 1999 and 2003). Fast-glycolytic fibres (see later for details), on the other hand, being relatively the largest fibre type are a major fibre type for muscle hypertrophy as well as in the predisposition of pale, soft and exudative (PSE) pork independent of ryanodine receptor 1 mutation.

In the living animal, muscle phenotype is a major factor in the functional integrity of mobility and movement, as well as of thermoregulation, which in turn governs its quality of life. A wide range of disease conditions often adversely affect muscle phenotype and lead to debilitating muscle wasting or atrophy. For instance, in human obesity, triglyceride accumulation in muscle (intramuscular fat) appears to be related to the development of insulin resistance and type 2 diabetes (Morio et al., 2001; Kelley et al., 2002; Wolfe, 2006). Hence, knowledge of the molecular events that affect muscle phenotype is of fundamental, agricultural, welfare and biomedical importance. By understanding the signalling processes and gene targets that effect muscle phenotype, strategic approaches, such as the use of marker-assisted selection (Beuzen et al., 2000), dietary manipulation (Casser-Malek et al., 2004) or even pharmacological targeting of novel effector genes, could be developed to improve muscle quality and quantity. 
This review endeavours to bring together recent advances in our understanding of the signalling pathways, and molecular mechanisms of several major growth promoting factors that affect muscle fibre phenotype relevant to farm animal production. Given that the subject area covered is wide, its purposes are to provide the reader with a general overview of the molecular aspects of muscle phenotype determination in the live animal and to highlight avenues for future research exploitation.

\section{What is muscle fibre phenotype?}

Post-natal muscle is a highly heterogeneous syncytial tissue, comprising muscle fibres and extracellular matrix, with the ability to rapidly undergo biochemical and physical fibre changes in response to appropriate external stimuli, such as nervous and hormonal stimulations, to adapt to the accompanying functional demands imposed on it (Caiozzo, 2004). The feature of functional plasticity indicates that skeletal muscle is highly amenable to changes in coordinated gene expression. Although the extracellular matrix of muscle, as exemplified by the orderly arrangement of endomycium, perimycium and epimycium, is a key determinant of meat quality (Fang et al., 1999; McCormick, 1999), this review is focussed on the regulation of muscle fibre phenotype. The physical and biochemical characteristics of muscle fibres can be conveniently defined under three distinct but overlapping categories: fibre number, fibre size and fibre type (Figure 1). Fibre types reflect differences in their biochemical (metabolic) and biophysical properties that arise from differences in coordinated expression of muscle gene isoforms (Schiaffino and Reggiani, 1996).

A feature of muscle fibre phenotype regulation that will be apparent is that the same signalling factor or pathway (such as IGF-1) can often have multiple phenotypic effects with regard to its influence on fibre number, size and type.

\section{Muscle formation and regeneration}

In vertebrates, most skeletal muscles are derived from muscle progenitor or precursor cells present in somites, which arise by segmentation of the paraxial mesoderm, located on either side of the notochord and neural tube in the early embryo. As it develops, each somite can be divided into the epaxial dermomyotome, which gives rise to the epaxial muscles, and into the hypaxial dermomyotome, from which derives the rest of the body

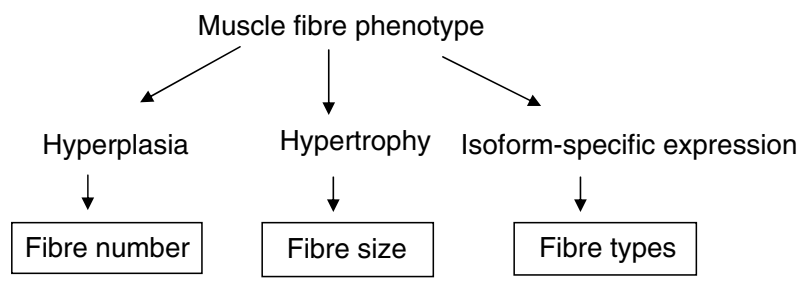

Figure 1 Categories of skeletal muscle fibre phenotype. and limb muscles. The first muscle mass to form, under the dermomyotome, is the myotome, which contributes to the trunk muscles. The early developmental events surrounding myogenesis are under intense molecular scrutiny (Buckingham, 2001). Myogenic cell fate specification is acquired from the activation of myogenic determination genes, namely the basic helix-loop-helix (bHLH) proteins encoded by Myf-5 and MyoD. The other two members of the myogenic bHLH gene family, myogenin and Mrf4, are implicated, along with $M y o D$, in the subsequent activation of muscle-specific genes during myogenic differentiation. MEF-2 family, characterised by the presence of a MADSbox motif, also plays an important role in muscle differentiation (Buckingham et al., 2003). Prior to the activation of Myf-5 or MyoD, signallings by Wnts, produced by the dorsal neural tube and surface ectoderm, and hedgehog (Hh) proteins, from the notochord and floor plate of the neural tube, are needed to serve as early triggers or inductive signals of myogenesis (Tajbakhsh and Buckingham, 2000). Hh signalling plays an additional role in committing progenitor cells to the slow-twitch lineage, a process specified by Blimp-1, originally identified as a factor that promotes B-cell maturation (Baxendale et al., 2004).

In limb muscle development, muscle progenitor cells opposite the limb buds must first delaminate from the hypaxial dermomyotome and migrate into the limb region. A number of homeobox proteins have been found to be essential for this migrational process (e.g. Pax3, c-met and its ligand hepatocyte growth factor (HGF)/scatter factor, and Lbx1) (Buckingham et al., 2003). Upon arriving at their destination, they begin to express MyoD and Myf-5 to mark the onset of myogenesis.

After appropriate rounds of cell proliferation, myoblasts leave the cell cycle and fuse to form multinucleated myotubes. The homeobox proteins of Mox2 and Msx1, and several growth factors, including insulin-like growth factor (IGF)-1 and -2 (Morali et al., 2000), fibroblast growth factors (FGFs), bone morphogenic proteins (BMPs) and platelet-derived growth factors, variously contribute to the regulation of proliferation and differentiation (Zorzano et al., 2003). The first muscle fibres that appear are known as primary fibres (around gestation day 35 in the pig and 12.5 days in the mouse), around which subsequent secondary fast fibres form at the time when innervation begins to be established (beginning at day 50 to day 87 in the pig and day 15 in the mouse) (Picard et al., 2002; Buckingham et al., 2003; Da Costa et al., 2003; Caiozzo, 2004).

As post-mitotic cells, skeletal muscle fibres are unable to undergo self-replication. Damaged fibres are replaced with newly synthesised fibres through the proliferation, differentiation and subsequent fusion of muscle satellite cells (myoblasts). Satellite cells constitute a reservoir of undifferentiated muscle precursor cells, located between the basal lamina and the sarcolemma, that are activated in response to muscle injury or growth stimuli to proliferate and ultimately fuse to generate new fibres. Muscle satellite cells are characterised by the expression of myostatin, 
a transforming growth factor (TGF)- $\beta$ like factor implicated in limiting muscle growth, c-met, Myf-5 and Pax-7 (Buckingham, 2001; Buckingham et al., 2003). It appears that not all muscle satellite cells are derived from somitic cells. There exists other population(s) of muscle precursor cells in skeletal muscle, the adult muscle stem cells, with haematopoietic and myogenic potentials (Asakura, 2003; Relaix, 2006). These adult muscle stem cells express haematopoietic markers, such as c-kit, CD45, CD34 and Sca1 (markers that are absent on satellite cells) but not myogenic markers like Pax7 and Myf-5 (present in satellite cells) (Asakura, 2003; Polesskaya et al., 2003). Recent work suggests that during growth and regeneration, adult stem cells proliferate and undergo phenotypic conversion, which involves Wnt signalling, into myogenic satellite cells (Asakura, 2003; Polesskaya et al., 2003). It is increasingly apparent that many of the regulatory genes involved in embryonic myogenesis are also required in post-natal muscle fibre formation by satellite cells.

\section{Fibre number: mediators of muscle hyperplasia}

It is generally regarded that by birth, an animal, such as the pig, would have nearly the same number of muscle fibres as in adulthood (Wigmore and Stickland, 1983). Therefore, the extent of fibre number formation or hyperplasia during foetal development will have a major bearing on muscle growth potential. In post-natal muscle, fibre number may not necessarily be constant. Periodic repair and replacement of damaged fibres are necessary to maintain functional integrity, a process performed by satellite cells that can proliferate and fuse with damaged fibres or fuse to form new fibres (Goldring et al., 2002). The relative contribution of satellite cells to the formation of new fibres (hyperplastic growth) and to existing fibres (hypertrophic growth) is not clear, but is likely to be dependent on the nature of the inductive signals. Fibre number determination can be affected by any factor that plays a role in embryonic or post-natal myogenesis through myoblast specification, proliferation and/or differentiation. The main signalling factors to be considered that affect fibre number are IGF-1 and -2 , myostatin and nutrition.

IGF-1 and IGF-2 activate Erk-MAPK pathway of cell proliferation (hyperplasia)

Growth factors such as IGFs and FGF by virtue of their ability to stimulate cell proliferation are regarded as potent agents that can affect fibre number, pre- and post-natally (Bass et al., 1999). Indeed, daily injections of growth hormone $(\mathrm{GH})$ in the sow during early pregnancy has been shown to enhance foetal fibre number (Rehfeldt et al., 2001), an effect likely to be mediated by IGF-1. IGF-1 and -2 stimulate both muscle cell proliferation and differentiation through the interaction with the type 1 IGF receptor (IGF1R), insulin receptor exon 11- (IR-A) and insulin receptor exon11 + (IR-B), all of which are transmembrane tyrosine kinase receptors (Denley et al., 2005). These activated receptors initiate two major signalling cascades (Figures 2 and 3). The type 2 IGF receptor (IGF-2R) (known also as mannose-6-phosphate receptor) and a family of high affinity IGF binding proteins (IGFBPs) 1 to 6 modulate the availability of IGF-1 and IGF2 to bind to receptors. IGF-2R has no intrinsic signalling transduction capability and serves to sequester IGF-2 from potential receptor interactions and to internalise and degrade IGF-2 (Denley et al., 2005). Liver is the main endocrine source of IGF-1 (IGF-1Ea), which is induced by GH. Additionally, damaged, stretched or loadbearing muscles are local sources IGF-1 and IGF-2 which induce proliferation and hypertrophy in an autocrine / paracrine manner (Adams, 2002). Besides the major IGF-1Ea isoform, a spliced variant with a carboxyl terminus different from IGF-1Ea, named MGF (mechano growth factor), is rapidly inducible in skeletal muscle and appears to be an early trigger for satellite cell proliferation (Yang and Goldspink, 2002). The autocrine / paracrine muscle production of IGF-2 during muscle differentiation and regeneration was found to participate in a positive feedback loop to further enhance muscle differentiation (Erbay et al., 2003; Wilson et al., 2003) and regeneration (Kirk et al., 2003). Although both IGF-1 and -2 are clearly important to muscle growth, their relative contribution to cell proliferation, differentiation and hypertrophy is uncertain.

IGF-1 (as well as insulin and IGF-2) binding activates the receptor tyrosine kinase (IGF1R or insulin receptor), which subsequently recruits insulin receptor substrate 1 (IRS-1), a non-enzymatic docking protein that propagates the signal to two crucial signalling pathways, the mitogenactivated protein kinase (Erk-MAPK) pathway, via Ras-RafMEK-Erk (Rommel et al., 1999; Zimmermann and Moelling, 1999; Glass, 2003a) and the phosphatidylinositol 3'-kinase (PI3K)-Akt1 pathway (Glass, 2003b; Vollenweider, 2003). The Ras-Erk MAP kinase (Erk-MAPK) pathway, a serine/ threonine phosphorylation cascade, is responsible for cell proliferation and plays an important role in hyperplastic growth (Figure 2). The PI3K-Akt1 pathway is a major route to muscle differentiation and hypertrophy (see later section). Ras is a membrane bound GTPase, and cycles between an inactive Ras-GDP to an active Ras-GTP. Expression of oncogenic Ras inhibits myogenic differentiation (Mitin et al., 2001) in part by promoting cell proliferation via the MAP kinase pathway. Interestingly, activated Ras was also found to induce the expression of slow myosin heavy chain (MyHC), although the downstream mechanism that leads to this fibre type-specific effect is not understood (Murgia et al., 2000). Both ErkMAPK and PI3K-Akt1 pathways are necessary and complement each other in mediating post-natal muscle growth (Haddad and Adams, 2004).

\section{Myostatin inhibits cell proliferation}

Myostatin (Mst), also known as growth and differentiation factor 8 (GDF-8), is a secreted negative regulator of muscle 

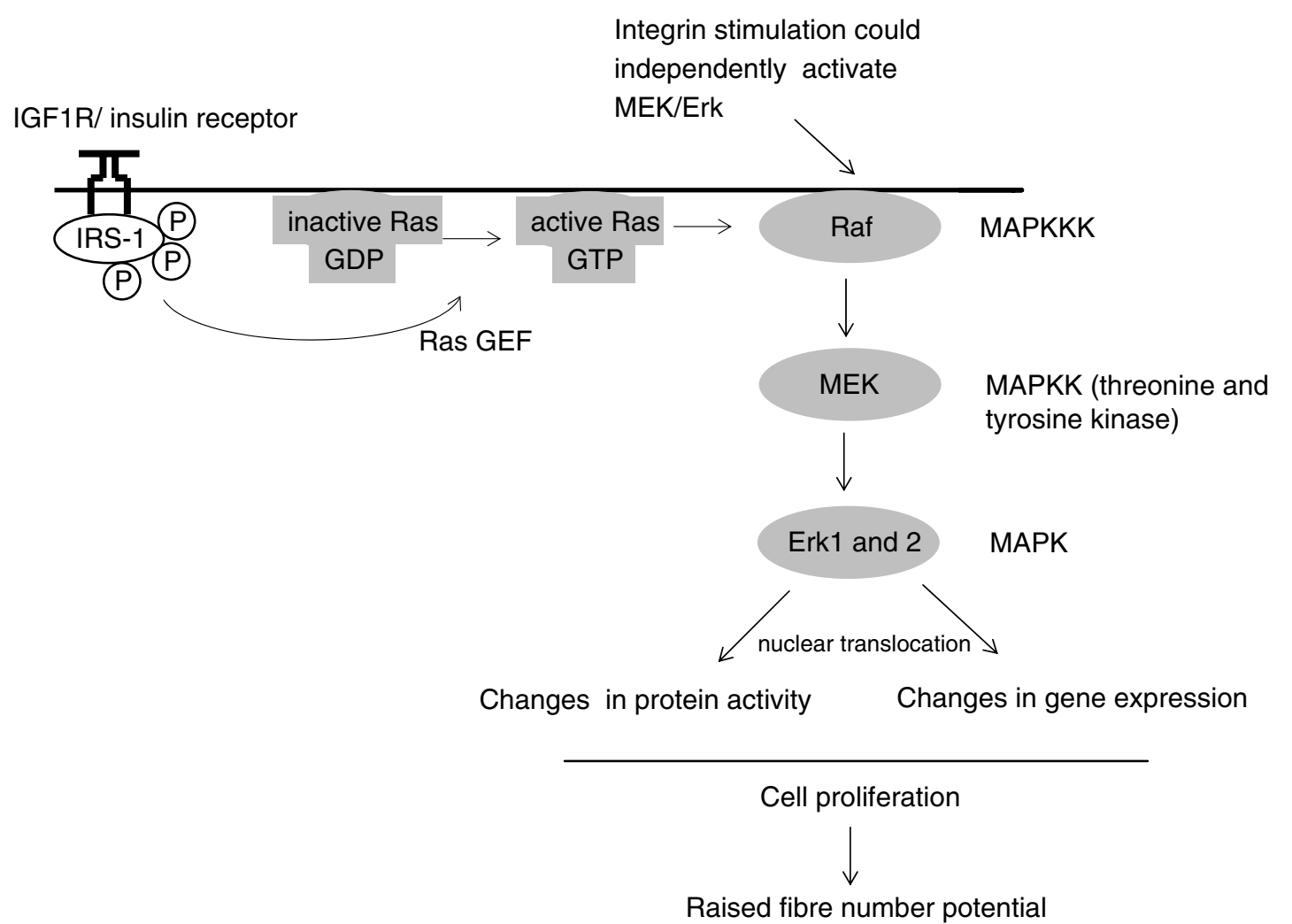

Figure 2 The IGF-induced Erk-MAPK proliferation signalling pathway of hyperplasia. IGF-1, IGF-2 or insulin binding to tyrosine kinase receptor triggers a phosphorylation cascade that leads to transcriptional and protein modifications, culminating in increase cell proliferation. Integrin can also activate the Erk-MAPK pathway independent of tyrosine kinase receptor binding. Note that activated Ras can also activate the PI3K pathway.

mass that belongs to the transforming growth factor (TGF)- $\beta$ superfamily (Kocamis and Killefer, 2002). Its biological significance is demonstrated in several breeds of double-muscling cattle (e.g. Belgian Blue and Piedmontese) and Mst-null mice as dramatic increase of muscularity through fibre hypertrophy and hyperplasia (Grobet et al., 1997; McPherron and Lee, 1997; Marchitelli et al., 2003). The Belgian Blue carries a naturally occurring homozygous 11-bp deletion in the coding region of Mst whereas the Piedmontese possesses a homozygous $G \rightarrow A$ point mutation that changes the cysteine residue in Mst to a tyrosine (Kambadur et al., 1997). The porcine Mst gene has been molecularly cloned and characterised, but a mutation that confers the enlarged muscle phenotype has not been described (Ji et al., 1998). Mst arrests muscle cells in the $G_{1}$ and $G_{2}$ phases of the cell cycle, through the up-regulation of cyclin-dependent kinase (cdk) inhibitor p21 and down-regulation of cdk-2, thereby inhibiting cell proliferation (Thomas et al., 2000). This inhibition is mediated, at least in part, through the p38 MAPK stress response pathway (Philip et al., 2005) (Figure 4). Mst also appears to directly inhibit muscle differentiation by interfering with the activity of MyoD (Langley et al., 2002). Muscle wasting conditions, such through disease or disuse atrophy, are associated with elevated Mst in affected muscles (McCroskery et al., 2003). A primary effect of Mst inactivation in post-natal growth is an increase of satellite cell proliferation and differentiation (McCroskery et al., 2003). $\mathrm{GH}$, mediated through IGF-1, was shown to inhibit Mst expression in skeletal muscles and C2C12 myotubes (Liu et al., 2003). Conversely, Mst expression in porcine embryonic myogenic cells up-regulates the production of IGF binding protein-3 (IGFBP-3), which reduces the activities of IGF-1 and -2 (Kamanga-Sollo et al., 2003). These results suggest that the Mst and IGF signalling pathways are closely connected in an antagonistic manner.

Recent micro-array investigations further found that Mstnull mice exhibited raised Wnt4 expression which stimulated satellite cell proliferation (Steelman et al., 2006). The use of both micro-array and proteomic analyses showed a clear fibre phenotype switch in Mst-null muscles from slow to fast-twitch fibres (Bouley et al., 2006; Steelman et al., 2006) (see section IGF-1, $\beta_{2}$-agonist and myostatin-null signal fast fibre phenotype). Mst has been recently found to promote adipogenesis in $\mathrm{C} 3 \mathrm{H} 10 \mathrm{~T}(1 / 2)$ cells which appears to be associated with adipocyte lineage commitment (Artaza et al., 2005). However, in committed bovine preadipocytes, Mst clearly suppresses differentiation of preadipocytes into adipocytes (Hirai et al., 2007).

Nutrition on fibre number and characteristics

Nutrition in animal growth is a complex subject of major importance, which due to its enormity cannot be fully 


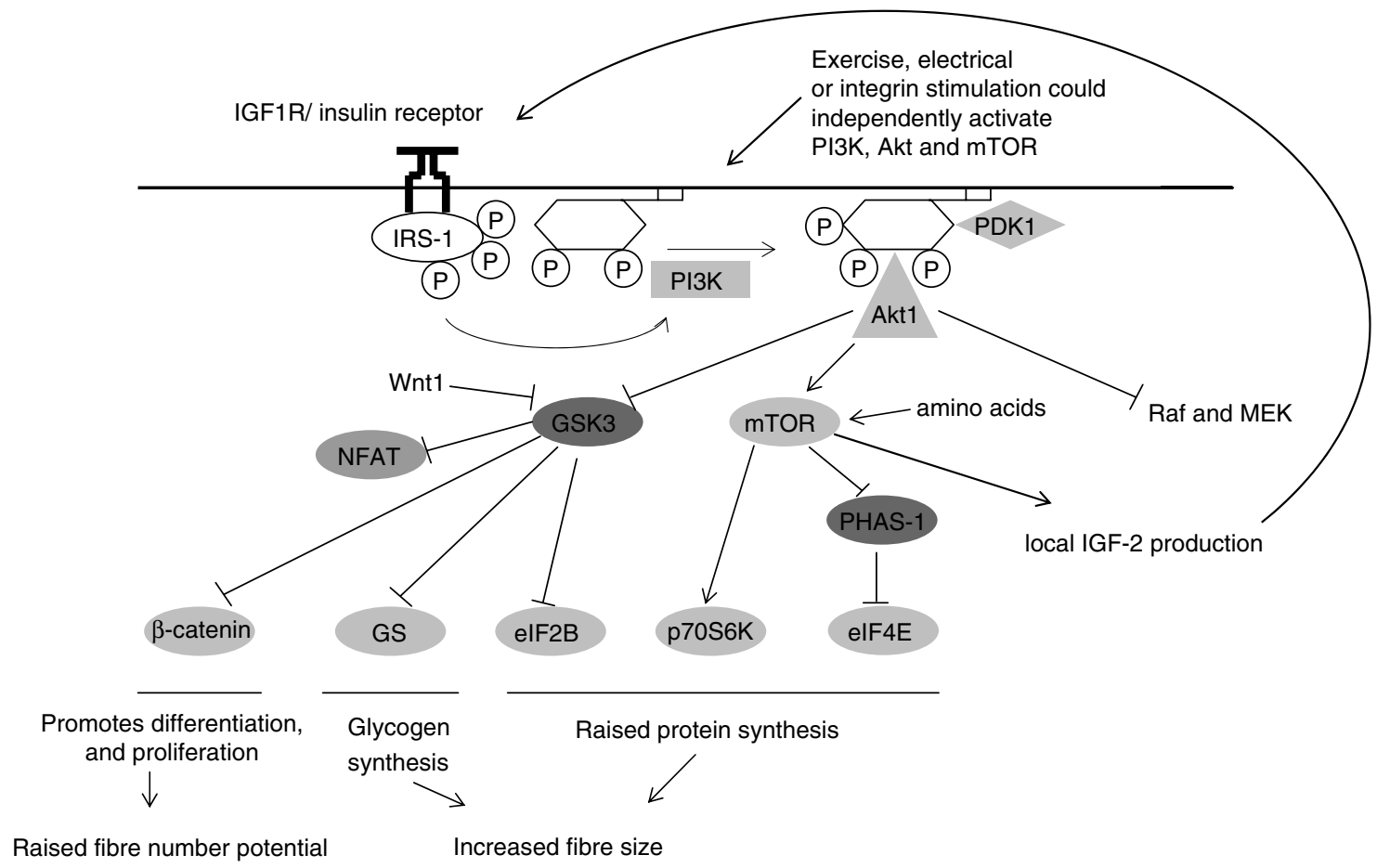

Figure 3 The IGF-induced PI3K-Akt1 signalling pathway of muscle differentiation and hypertrophy. It affects a range of cellular processes, including the promotion of protein synthesis, glycogen synthesis, and cell proliferation and differentiation, that culminate in muscle hypertrophy. mTOR can be activated by amino acids (nutrients) and induce local IGF-2 production which, in turn, acts in a positive feedback manner. The PI3K cascade can be independently activated by exercise and by integrin stimulation (see also integrin stimulation of Erk-MAPK pathway, Figure 2). Activated Akt1 via inhibiting Raf and MEK phosphorylation is involved in inhibitory crosstalk with the Erk-MAPK pathway. Selected abbreviations: PI3K = phosphatidylinositol $3^{\prime}-$-kinase, PDK1 = phosphatidylinositol-dependent protein kinase 1, GSK3 $\beta=$ glycogen synthase kinase $3 \beta$, mTOR $=$ mammalian target of rapamycin, GS $=$ glycogen synthase, and p70S6K = ribosomal protein S6 kinase. Note that Akt, GSK3ß, mTOR, p70S6k and PHAS-1 are serine/threonine kinases.

addressed in the present review. Maternal nutrition is undoubtedly a key factor in foetal growth and its subsequent survival which manifests its effects through a complex signalling network that includes IGFs (Hornick et al., 2000; Maak et al., 2001; Wu et al., 2006). However, in the context of foetal fibre number, the precise role of maternal nutrition is not entirely clear. Earlier work suggests that doubling food intake during early sow pregnancy increases the number of secondary fibres in the newborn, which would confer greater potential for post-natal growth (Dwyer et al., 1994). More recent work, however, could not reproduce this finding (Nissen et al., 2003).

Connected to nutrition, mild dietary restriction on beef cattle has little apparent effect on muscle characteristics or meat quality (Casser-Malek et al., 2004). However, dietary changes during weaning in calves appear to have an appreciable effect on increasing the number of oxidative fibres (Picard et al., 1995). Under moderate protein and energy dietary restriction (20\% less protein and $7 \%$ less energy) in young growing pigs, we recently found, with the use of a porcine CDNA muscle micro-array, significant increase in the accumulation of intramuscular fat, which could have production implications on meat quality ( $\mathrm{Da}$ Costa et al., 2004). A similar dietary restriction study has been reported on Brahman cattle but no data on meat characteristics are provided (Byrne et al., 2005). Lamb and beef animals raised on grass showed greater flavour intensity in comparison with grain-fed animals because of a higher accumulation of 18:3 polyunsaturated fatty acids from a grass diet (Wood et al., 1999).

\section{Fibre size: mediators of muscle hypertrophy/atrophy}

Post-natal muscle growth is primarily a function of enlargement and elongation of existing fibres as a result of net protein synthesis, known as muscle hypertrophy (Figure 1) (Glass, 2003b). Conversely, loss of muscle mass as a consequence of disease or muscle inactivity is primarily due to a reduction in fibre size, described as muscle atrophy (Glass, 2003b). Muscle differentiation is a prerequisite to hypertrophy and, as detailed below, the same factors are often involved in both processes (differentiation and hypertrophy). In this section, we consider some well known signalling factors and pathways that mediate muscle hypertrophy or atrophy (IGF-PI3K pathway, contractile activity, p38 MAP kinase pathway, synthetic $\beta_{2}$ adrenergic agonists, anabolic steroids and ski proto-oncogene.

IGF activates PI3K-Akt1 pathway of hypertrophy The IGF-activated PI3K-Akt1 signalling pathway (Figure 3) is widely regarded as the primary route to skeletal muscle differentiation and hypertrophy (Coolican et al., 1997; Jiang et al., 1998; Glass, 2003b). Phosphatidylinositol 3'-kinase 


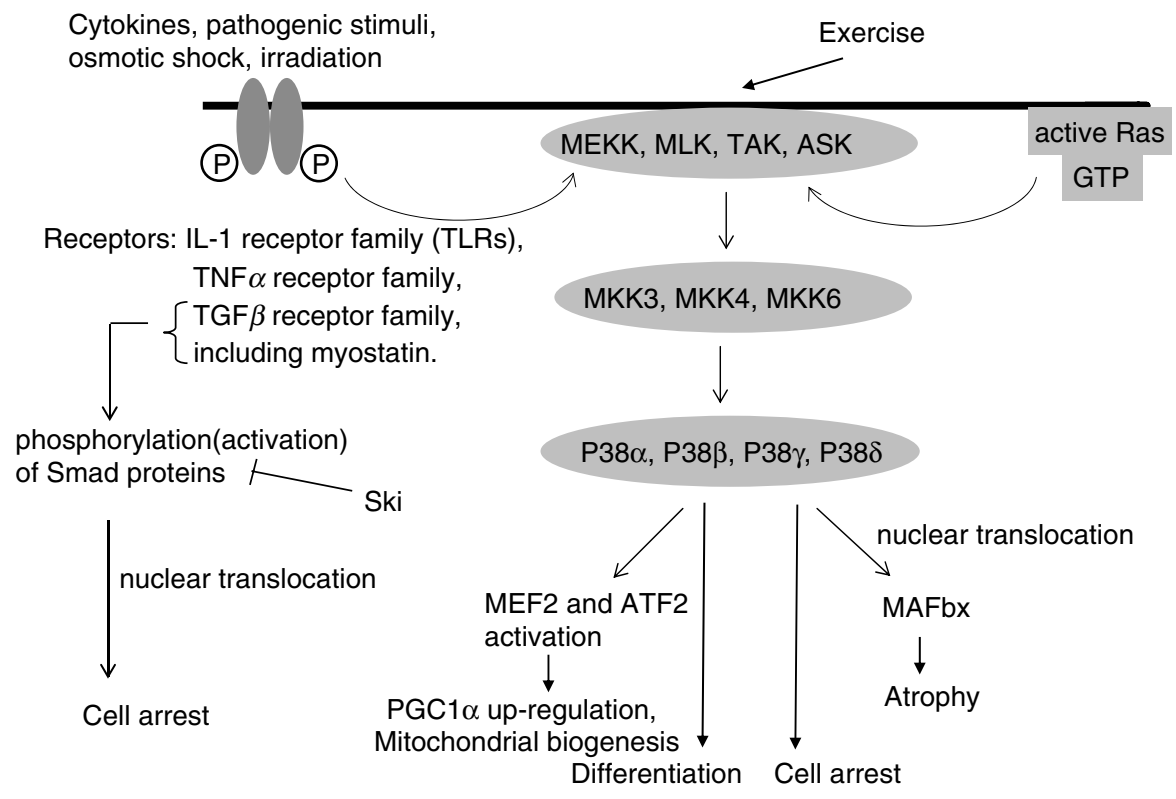

Figure 4 The p38 MAPK stress response pathway of cell arrest and atrophy. It is activated by a variety of stimuli, including exercise and activated Ras, and through different receptor families. It mediates a range of effects: cell arrest, differentiation, atrophy as well as mitochondrial biogenesis. Additionally, TGF $\beta$ receptors readily signal through Smad proteins which also lead to cell arrest. Ski functions to inhibit Smad signalling thus relieving cell arrest and promoting proliferation. Selected abbreviations: IL-1 $=$ interleukin 1, TLRs $=$ toll-like receptors, TNF $\alpha=$ tumour necrosis factor $\alpha$, and TAK $=$ TGF $\beta$-activated kinase.

(PI3K) is a dimeric lipid kinase that catalyses the phosphorylation of membrane-bound phosphatidylinositol $(4,5)$-bisphosphate $\left(\mathrm{PIP}_{2}\right)$ to phosphatidylinositol $(3,4,5)$ trisphosphate $\left(\mathrm{PIP}_{3}\right)$. $\mathrm{PIP}_{3}$ provides a membrane-binding site for Akt1 (also known as protein kinase B) a serine/threonine kinase, and phosphatidylinositol-dependent protein kinase 1 (PDK1) (Figure 3). Akt1 is phosphorylated by PDK1, and once activated Akt1 phosphorylates a number of substrates that are responsible for a range of growth processes, which include protein synthesis, glycogen synthesis, muscle differentiation and cell proliferation. A key target of activated Akt1 is the phosphorylation of mTOR (mammalian target of rapamycin), a serine/threonine kinase, which in turn activates a number of downstream effectors including ribosomal protein S6 kinase (p70S6K) and elF-4E, both of which mediate translation initiation and appear to play important roles in muscle hypertrophy. mTOR has also been shown to mediate myogenesis by a process that is independent of its kinase activity, although the exact mechanism involved is unclear (Erbay and Chen, 2001). During differentiation, mTOR was found to induce the local production of IGF-2, and it seems that the myogenic effect of mTOR is mediated in part through a positive feedback loop with IGF-2 (Erbay et al., 2003). There is evidence that mTOR can also be activated by amino acids, independent of Akt1 (Parkington et al., 2003) and that muscles of nutrient-restricted pregnant cows showed reduced phosphorylation activation of mTOR (Du et al., 2005).

Glycogen synthase kinase $3 \beta$ (GSK3 $\beta)$, a serine/threonine kinase, is another major substrate of activated Akt1 that modulates muscle hypertrophy (Figure 3). Like mTOR, GSK3 $\beta$ can also be phosphorylated independent of Akt1.
Activation of protein kinase $A$ or $C$ is able to lead to the phosphorylation of GSK3 $\beta$ (Jope, 2003). Unstimulated (dephosphorylated) GSK3 $\beta$ is active and its phosphorylation activity appears to act as a general repressor on its substrates. Many substrates of GSK3 $\beta$ have been identified, including glycogen synthase, c-Jun, cyclin D1, $\beta$-catenin, nuclear factors of activated T-cells (NFATs), and Notch2 (Masuda et al., 1998; Espinosa et al., 2003). The inhibition of GSK3 $\beta$ by phosphorylation, leads to dephosphorylation activation of glycogen synthase, resulting in glycogen synthesis, and to activation of elF-2B, which promotes protein synthesis (Rommel et al., 2001). A primary effect of GSK3 $\beta$ inhibition on muscle is the promotion of hypertrophy (Rommel et al., 2001; Vyas et al., 2002). Clearly, with its wide range of targets, GSK3 $\beta$ can mediate a host of other effects. GSK3 $\beta$ inhibition, by lithium chloride, improves glucose uptake of muscle cells, which makes it a pharmacological target for the treatment of diabetes (MacAulay et al., 2003). Wnt signalling leads to the inhibition of GSK3 $\beta$, an integral component of the linear cascade that results in the stabilisation of $\beta$-catenin, a coactivator necessary for cell proliferation (Novak and Dedhar, 1999; Giles et al., 2003) and myogenic differentiation (Martin et al., 2002; Petropoulos and Skerjanc, 2002; Shi et al., 2002). Hence the inhibition of GSK3 $\beta$ facilitates cell proliferation, muscle differentiation (via $\beta$-catenin) and, subsequently, hypertrophy.

\section{Contractile activity and integrins}

Muscle hypertrophy can be an adaptive response to loadbearing exercise, which stimulates the local expression of 
IGF-1, a potent inducer of muscle hyperplasia and hypertrophy. There is also growing evidence that key signalling intermediates in the Erk-MAPK and PI3K-Akt1 pathways can be activated independent of growth factor stimulation (Figures 2 and 3). Integrins are heterodimeric $(\alpha \beta)$ transmembrane adhesion proteins that link the actin cytoskeleton to the extracellular matrix, and participate in a vast array of signalling events including mechanical sensing, cell growth and cell migration. Stimulation of $\beta_{3}$ integrin by a synthetic Arg-Gly-Asp ligand in feline cardiomycytes led to activation of PI3K, mTOR, p70S6K and MEK/Erk (Balasubramanian and Kuppuswamy, 2003). It appears that in rats exposed to certain treadmill running regimes, and in certain isolated muscles subjected to passive stretch, Akt1 can be independently activated (Sakamoto et al., 2003). mTOR, but not Akt1, was also found to be activated in rat hindlimb muscles subjected to 6 hours of high frequency electrical stimulation (Parkington et al., 2003). Hence exercise or electrical stimulation can variously activate the ErkMAPK and PI3K-Akt1 pathways as well as the p38 MAPK cascade (see next section) in the regulation of muscle development.

\section{p38 MAP kinase pathway of cell arrest and atrophy}

p38 MAP kinase represents another MAPK signal transduction pathway that is activated by cellular stress (e.g. heat shock, oxidative stress and certain cytokines) as well as insulin (Conejo et al., 2001; Lee et al., 2002). The p38 MAPK pathway is intriguing in that it appears to mediate a range of cellular processes in muscle besides fibre size (Figure 4). There are four members of the p38 MAP kinase family: p38 MAPK- $\alpha,-\beta,-\gamma$ and $-\delta$. The dual specificity kinases, MKK3 and MKK6, are involved in p38 MAP kinase activation, with MKK3 activating p38 MAPK $\alpha$ and $\beta$, and MKK6 activating all four p38 MAPK isoforms (Lee et al., 2002) (Figure 4). A variety of receptor families (including interleukin-1 [IL-1], tumour necrosis factor $\alpha$ [TNF $\alpha$ ] and TGF $\beta$ ) signal through this cascade. Signalling of p38 MAPK has been reported to be essential for terminal differentiation (myoblasts fusion into myotubes), by enhancing the expression of MyoD, MEF2A, MEF2C, sarcomeric muscle genes and cdk inhibitor p21 (Cabane et al., 2003; Wu et al., 2000c). p38 MAPK has the added role of inhibiting the Erk-MAPK pathway thereby inducing cell cycle arrest during muscle differentiation (Lee et al., 2002). It is interesting to note that the Erk-MAPK pathway is also inhibited by activated Akt1 through the prevention of Raf and MEK phosphorylation (Rommel et al., 1999; Zimmermann and Moelling, 1999)(Figure 3). TNF- $\alpha$ stimulated p38 MAPK signalling up-regulates MAFbx mRNA expression, which codes for a major E3 ubiquitin ligase responsible for muscle atrophy (Li et al., 2005) (see section on markers of atrophy and hypertrophy). Exercise induced p38 MAPK signalling has been shown to stimulate $P G C-1 \alpha$ expression which leads to mitochondrial biogenesis hence promoting oxidative capacity (Akimoto et al., 2005). Furthermore, we recently found that the p38 MAPK pathway performs an important role in the activation of the fast oxidative-glycolytic MyHC 2x promoter in skeletal muscle (J.D. Meissner et al., unpublished data). Hence, depending on the nature of p38 MAPK stimulation, different phenotypic outcomes, such as cell arrest, atrophy, terminal differentiation or raised oxidative capacity, can result from this pathway (Figure 4).

\section{Synthetic $\beta_{2}$ adrenergic agonists}

$\beta_{2}$ adrenergic receptor agonists ( $\beta_{2}$-agonists), such as clenbuterol, cimaterol and fenoterol, are potent agents for muscle hypertrophy as well as fibre type switch from slow/l to fast fibres (Ryall et al., 2002). They are also important regulators of T-cells development in the thymus (Blanco et al., 2003), and were primarily developed for use as smooth muscle bronchodilators (Ryall et al., 2002). A feature of $\beta$ adrenergic receptors signalling, through the binding of catecholamines, is triglyceride hydrolysis, a process that has been harnessed in animal production to produce leaner carcasses. Ractopamine ('Paylean', Elanco), a $\beta_{1}$ - and $\beta_{2}$-agonist, is a commercial compound sold in the USA as a promoter of lean growing pigs (Mills et al., 2003). $\beta_{2}$-adrenergic receptor but not $\beta 1$ adrenergic receptor is responsible for mediating the hypertrophic effect of clenbuterol (Hinkle et al., 2002). The growth promoting efficacy of $\beta_{2}$-agonists appears to show animal species variation; ruminants display the greatest and broiler chickens the least response, with pigs occupying an intermediate position (Mersmann, 1998). Although the effects of $\beta$-agonists on meat quality are somewhat equivocal, the overall picture, in particular in the pig, is that many $\beta$-agonists decrease intramuscular fat and increase shear force or toughness (Dunshea et al., 2005).

The signalling events of $\beta_{2}$-agonists leading to muscle hypertrophy is poorly understood. There is evidence to suggest that clenbuterol induces local muscle production of IGF-1, which mediates hypertrophy (Awede et al., 2002). More recent work, however, could not detect sustained local production of IGF-1 in rat muscles treated with clenbuterol but a reduction in the expression of components of the ubiquitin-proteasome pathway was found (Yimlamai et al., 2005). The use of clenbuterol in meat production or in the treatment of muscle wasting conditions, however, has been impaired by reports of possible side effects. Pigs treated with anabolic doses of clenbuterol showed immunosuppressive effects, with raised T-cell apoptotic index (Blanco et al., 2003) and testicular degeneration (Blanco et al., 2002). In the pig, the hypertrophic effect of clenbuterol on muscle was short-lived after drug withdrawal, which could render its use ineffective in the growth promotion of food animals (Sillence et al., 2002). In rats, clenbuterol was found to cause significant cardiac and skeletal muscle necrosis (Burniston et al., 2002).

\section{Anabolic steroids}

Testosterone is an important male hormone whose effects on body composition are to increase muscle mass and 
reduce fat, effects that are not dissimilar to $\beta_{2}$-agonists (Kutscher et al., 2002). Testosterone administration is associated with hypertrophy of type 1 and 2 fibres, and increases in satellite cell number in humans and some animals (Sinha-Hikim et al., 2003; Chen et al., 2005). In porcine satellite cells, however, the effect of testosterone on proliferation rate is equivocal (Doumit et al., 1996). Anabolic androgenic steroids (stanozolol and nandrolone), made notorious by their misuse in sports, are structural synthetic derivatives of testosterone, designed to maximise anabolic and reduce androgenic (male sexual) effects. Outside the European Union, where anabolic steroids are used in beef production, meat quality can be adversely affected by a small but significant rise in shear force (Dunshea et al., 2005). Little is known about the anabolic steroidinduced signalling mechanisms that regulate muscle mass. One of the primary anabolic effects of androgens may be their ability to stimulate localised IGF-1 production in skeletal muscle (Chen et al., 2005).

\section{Ski}

Ski is a nuclear proto-oncogene that is essential for embryonic development. It is expressed in most post-natal tissues. Like IGF-1, it exhibits dual functions in promoting cell proliferation and muscle differentiation. In addition to transforming chicken embryo fibroblasts, Ski can induce cells derived from quail embryonic body wall to undergo myogenesis. Lines of transgenic mice carrying chicken Ski CDNAs under the control of murine sarcoma virus (MSV) long terminal repeat (LTR) preferentially express high levels of Ski mRNA and protein in skeletal muscle, even though MSV-LTR is usually active in other tissues (Sutrave et al., 1990 and 2000). This near exclusive skeletal muscle expression of Ski is associated with hypertrophy of fast glycolytic $2 b$ fibres, without increase in fibre number or nuclear number (Sutrave et al., 1990). The hypertrophic effect of $S k i$ on $2 \mathrm{~b}$ fibres is associated with reduced protein degradation rates (Costelli et al., 2003). It could be that Ski over-expression is deleterious to cells, which would account for its restricted distribution of expression in MSVLTR-Ski transgenic mice, and an absence of expression in skeletal- $\alpha$-actin promoter-driven $S k i$ transgenic mice (Sutrave et al., 2000). Indeed, satellite cells isolated from muscles of MSV-LTR-Ski transgenic mice showed accelerated deterioration in termination differentiation with increasing age (Charge et al., 2002).

Unlike other oncogenes, the over-expression of the wild type c-Ski is sufficient to cause transformation (Prunier et al., 2003). The oncoproteins from Ski and the related SnoN (ski-related novel gene) are able to interact with a variety of transcription regulatory complexes, including histone deacetylase complexes (HDACs) and tumour suppressors (Ueki and Hayman, 2003). The TGF- $\beta$ signalling pathway has been identified as a key interacting site of $S k i$. The regulation of cell growth and differentiation by TGF- $\beta$ is mediated by the Smad proteins, which are important tumour suppressors. TGF- $\beta$ signalling is initiated when the bound ligand induces the formation of a heteromeric complex comprising type I and type II serine/threonine receptors. Type II receptor transphosphorylates type I receptor, which in turn phosphorylates Smad2 and Smad3. Activated Smad2 and Smad3 form heterodimers with Smad4 and translocate into the nucleus where they interact with a host of complexes to bring about transcriptional activation or repression of specific genes (Figure 4). Ski was recently found to directly interact with Smad2, Smad3 and Smad4, and to block the phosphorylation of Smad2 and Smad3 by activated TGF- $\beta$ type I receptor (Prunier et al., 2003; Ueki and Hayman, 2003). Therefore, a mechanism of the transforming ability of Ski (and SnoN) is the repression of Smad function, whose inactivation prevents TGF- $\beta$-induced cell cycle arrest. The up-regulation of $S k i$ in proliferating satellite cells points to its possible role in mediating cell proliferation in the regeneration of damaged fibres (Soeta et al., 2001). The mechanisms behind the effects of Ski on muscle differentiation and hypertrophy are unknown. One speculation is that Ski inhibits the signalling of myostatin, a member of the TGF- $\beta$ superfamily, thereby enhancing cell proliferation and differentiation (Costelli et al., 2003) (Figure 4). Ski might be developed as a candidate marker for hypertrophic growth in markerassisted selection.

\section{Fibre types: coordinated isoform-specific expression}

The plasticity of muscle fibres is not confined to its ability to undergo changes in fibre size. Physiological and biochemical properties can show wide variations between individual fibres, and such variations are further subjected to modulations by external stimuli. Traditionally, classification of muscle fibre types is based on differences in a number of biochemical parameters between fibres (Gil et al., 2001; Zierath and Hawley, 2006). Succinate dehydrogenase (SDH) histochemical staining, for example, is able to differentiate fibres into two or three different types, based on the relative amount of the enzyme present in each fibre. As SDH is an integral component of the citric acid cycle, strongly positive fibres are classified as oxidative fibres. Another commonly cited histochemical staining method depends on the overall myosin adenosine triphosphatase (ATPase) activity in each fibre (Brooke and Kaiser, 1970; Bancroft and Gamble, 2002). Myosin ATPase activity originates from myosin heavy chain (MyHC), the principal sacromeric protein component of the thick myofilament. Differential myosin ATPase staining is due to differences in susceptibility to $\mathrm{pH}$ between different MyHC isoforms. Since myosin ATPase is highly sensitive to $\mathrm{pH}$ change, this staining method is intrinsically prone to variability in results. Histochemical methods, such as SDH and myosin ATPase stainings, are invaluable in describing the biochemical profile of individual fibres. However, they are less reliable in the objective determination of fibre types. Different histochemical stains often provide slightly 
different classification outcome of individual fibres, which in the past had made findings of association studies between fibre types and meat quality traits variable and even contradictory (Essén-Gustavsson, 1993; Klont et al., 1998; Lefaucheur et al., 2004).

Definition of fibre types. A recent major advance in farm animal muscle research has been the development of an objective approach to muscle fibre typing based on the identity of the primary MyHC isoform expressed in each fibre (Chang et al., 1993 and 1995; Chang and Fernandes, 1997). MyHCs are encoded by a highly conserved multigene family, of which eight isoforms are known in mammals $(2 a, 2 x, 2 b$, embryonic, perinatal, slow/ $\beta$, extraocular and $\alpha$ ), each with its own myosin ATPase activity and each encoded by a distinct gene (Weiss and Leinwand, 1996). In pre-natal mammalian muscles, the embryonic, perinatal and slow/ $/$ type I MyHC isoforms represent the three dominant skeletal muscle fibre types in the developing foetus. Shortly after birth, the post-natal MyHC isoforms (2a, $2 x$ and $2 b)$ replace the expression of embryonic and perinatal MyHC genes. Thus, in post-natal muscles of pigs, dogs and rodents, there are four major fibre types (Figure 5) characterised by the expression of the slow/ $/$ type I, 2a, 2x and $2 \mathrm{~b}$ MyHC gene isoforms (Schiaffino and Reggiani, 1996; Wu et al., 2000b). In cattle and horses, MyHC $2 \mathrm{~b}$ fibres are effectively absent (Chikuni et al., 2004; Maccatrozzo et al., 2004). Based on the MyHC approach, post-natal muscle fibres in animals can be resolved by immunocytochemistry or in situ hybridisation into three or four major types, depending on animal species. Metabolic, biochemical and biophysical characteristics, such as oxidative and glycolytic capacities, fibre size, colour, and glycogen and lipid contents, have been found to vary between MyHC fibre types (Schiaffino and Reggiani, 1996; Klont et al., 1998; Karlsson et al., 1999) (Table 1). The slow/ $\beta$ and fast $2 b$ fibres, also known as slow oxidative (red) and fast glycolytic (white) respectively, represent two extreme metabolic profiles. Slow MyHC fibres are characterised by slow isoform contractile proteins, high levels of myoglobin, high volumes of mitochondria, high oxidative capacity, high lipid contents and high capillary density. Favourable meat traits such as colour and, in the pig in particular, tenderness have been found to closely associate with the greater abundance of red or highly oxidative fibres (Klont et al., 1998; Karlsson et al., 1999; Chang et al., 2003; Maltin et al., 2003; Wood et al., 2004). There is a general perception that leaner meat, especially pork, contains reduced intramuscular fat, resulting in increased toughness and reduced succulence (Dunshea et al., 2005). Red muscles possess higher lipid concentration (intra- and inter-fibre fat) which is associated with more tender / juicy meat (Hocquette et al., 1998;Wood et al., 1999 and 2003).

By contrast, fast MyHC $2 b$ fibres are the largest of the four fibre types with fast isoform contractile proteins, low amounts of myoglobin and mitochondria, high glycolytic capacity (high glycogen store), low lipid contents and low capillary density. The fast MyHC $2 a$ and $2 x$ fibres are intermediate fast oxidative-glycolytic fibres. Fast $2 a$ fibres are more closely related to slow/l fibres, and fast $2 x$ are more similar to fast $2 b$ fibres (Table 1). Fast glycolytic fibres, in particular $2 \mathrm{~b}$ fibres, are major contributors of hypertrophic growth and of rapid fall in muscle $\mathrm{pH}$ post mortem, associated with the formation of PSE pork. Hence in the modern pig, hypertrophic growth potential (meat quantity) from an abundance of MyHC2b and $2 x$ fibres comes at a cost to
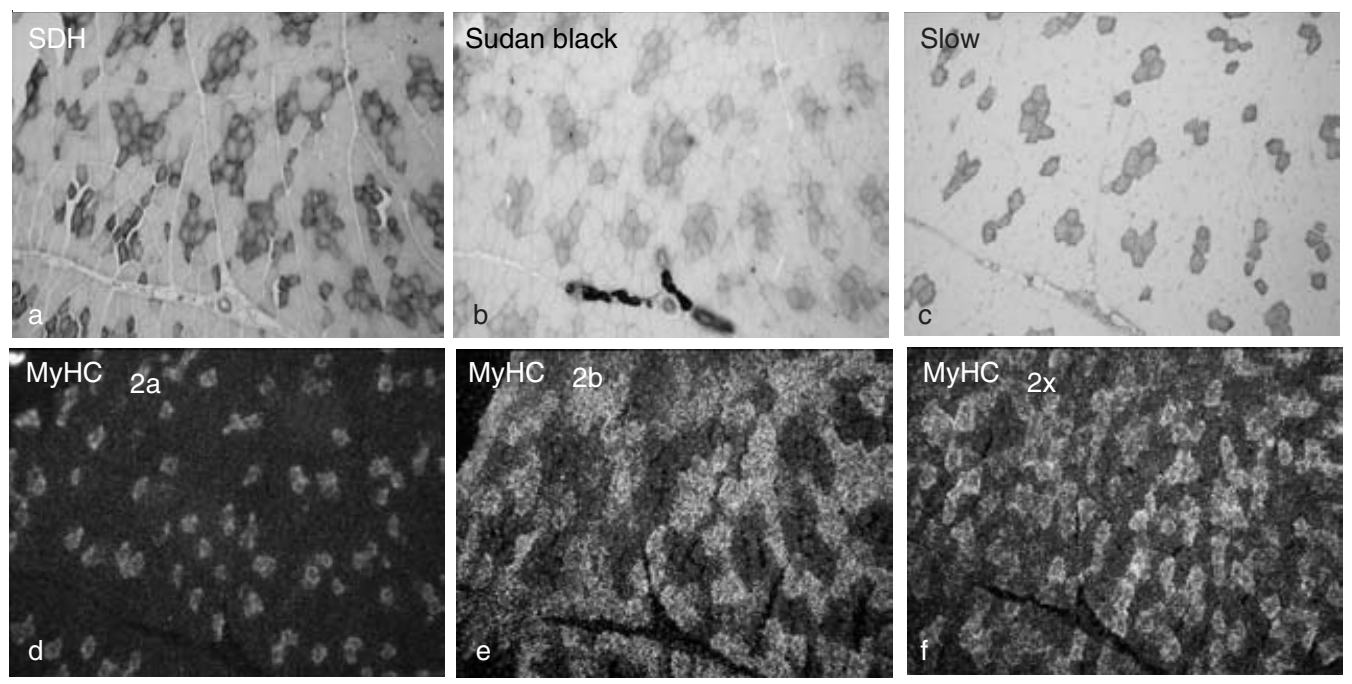

Figure 5 Typing of porcine muscle fibres. Serial sections of the psoas of a 22-week-old pig to illustrate the combined use of histochemistry, immunocytochemistry and in situ hybridisation to identify the four major post-natal MyHC fibre types. Succinate dehydrogenase (SDH) staining (a), sudan black staining (b), NOQ7.5.4D (slow) monoclonal antibody binding (c), and in situ hybridisations with MyHC isoform-specific fast 2a probe (d), fast $2 \mathrm{~b}$ (e) and fast $2 x$ probe (f) were performed. SDH and Sudan Black positive fibres closely mirrored each other and corresponded mainly to slow and fast $2 a$ fibres. Note the presence of inter-fibre adipose tissue on panel $b$. 


\begin{tabular}{lllll}
\hline \hline & & \multicolumn{3}{c}{ MyHC } \\
\cline { 2 - 5 } & Slow/beta & $2 \mathrm{a}$ & $2 \mathrm{x}$ & $2 \mathrm{~b}$ \\
\hline Type & Slow-oxidative & Fast oxidative-glycolytic & Fast oxidative-glycolytic & Fast glycolytic \\
Size & ++ & $(++)$ & $(++)$ & +++ \\
Glycogen & $(+)$ & $(++)$ & $(++)$ & $(+++$ \\
Lipids & +++ & ++ & $(+)$ & $(+)$ \\
Fatigue & Resistant & Intermediate & Intermediate & Sensitive \\
PSE $^{\dagger}$ & Resistant & Intermediate & Intermediate & Prone \\
\hline \hline
\end{tabular}

${ }^{\dagger}$ Pale, soft exudative (PSE) meat quality, independent of ryanodine receptor mutation. The abundance of MyHC $2 \mathrm{~b}$ fibres in a normal pig is a contributory factor to PSE. () indicates possibly variable levels or data not fully established in the pig.

meat quality (Chang et al., 2003). On the other hand, the absence of MyHC $2 \mathrm{~b}$ fibres in cattle is a likely explanation for the lack of a PSE problem in beef. Some beef studies have linked an abundance of fast-twitch fibres (defined by histochemical detection) to improved tenderness. The interpretation of fast-twitch fibres should be made with care as it is presently clear that in the absence of MyHC $2 \mathrm{~b}$ fibres there are strictly speaking no fast-glycolytic fibres in bovine muscle (Geay et al., 2001; Maltin et al., 2003). Consequently, in a technical sense, bovine muscle may have higher oxidative potential than its porcine counterpart.

In addition to temporal regulation, each $\mathrm{MyHC}$ isoform is subjected to specific spatial control, such that the number and distribution of fibres expressing each isoform often vary between anatomical muscles, e.g. soleus and longissimus thoracis et lumborum (also referred by some as longissimus dorsi). Fibre type composition varies between muscles according to their functional adaptation. Postural muscles are under continual use and comprise a high proportion of oxidative fibres. Muscles that are periodically used for intensive activities like sprinting possess large numbers of fast fibres. A further degree of fibre type heterogeneity is the presence of a small number of hybrid MyHC fibres, usually presented as a mixture of two MyHC isoforms (slow/2a, 2a/2x, or $2 x / 2 b$ ) (Sant'ana Pereira et al., 1995; Pette and Staron, 2000). Thus fibre population in muscle is a continuum of pure and hybrid fibres that can be altered in the fast-to-slow or slow-to-fast direction under appropriate stimulatory conditions (Schiaffino and Reggiani, 1994).

Distinctive biochemical and biophysical differences between fibre types point to a coordinated programme of fibre-type or isoform specific expression (Hallauer and Hastings, 2002). However, compared with our knowledge of muscle hypertrophy, much less is known about the molecular mediators of fibre type specific expression. Coordinated fibre type specific expression requires the orchestrated regulation of a large number of gene isoforms consistent with the fibre phenotype. Gene family and differential splicing are features of muscle genes (Schiaffino and Reggiani, 1996). Understanding the complexities of fibre type specific expression, requires insights into the signalling pathways that coordinate the temporal and spatial distribution of expression of subsets of muscle gene isoforms. The emerging picture of fibre type specific regulation is that it is governed by multiple signalling pathways and factors rather than a single pathway (Spangenburg and Booth, 2003). These pathways and factors almost inevitably have additional cellular functions, such as proliferation, differentiation and hypertrophy, in addition to modulating fibre type specific expression.

IGF-1, $\beta_{2}$-agonists and myostatin-null signal fast fibre phenotype

As highlighted earlier, the major phenotypic effects of IGF-1 and -2 are cell proliferation, muscle differentiation and hypertrophy. Such properties of IGF-1 have been shown to be beneficial to ageing, atrophic, and dystrophic muscles (Barton-Davis et al., 1998; Lynch et al., 2001; Musarò et al., 2001). IGF-1 has the additional effect of converting fibres to a fast glycolytic phenotype, as evident by raised expression of glycolytic enzymes in IGF-1-transfected C2C12 myotubes (Semsarian et al., 1999), by modest rise in fast $2 b$ fibres in transgenic mice carrying muscle IGF-1 isoform driven by a rat myosin light chain (MLC)-1/3 promoter (Musarò et al., 2001) and by raised type $2 a$ and $2 b$ fibres at the expense of slow fibres in IGF-1-treated dystrophic mice (Lynch et al., 2001). As previously indicated, clenbuterol (a $\beta_{2}$-agonist) treated rats (Ryall et al., 2002) as well as myostatin-null mice (Steelman et al., 2006) not only showed muscle hypertrophy but also slow-to-fast fibre conversion. The mechanism responsible for the slow-to-fast fibre type switch, however, remains elusive. In general, in the pig and ruminants, it appears that growth hormone (indirectly IGF-1) and $\beta$-agonists may negatively affect meat quality, as shown by increased shear force or sensory perception (Dunshea et al., 2005). Such effects may be connected to increased fast glycolytic (MyHC $2 \mathrm{~b}$ or $2 x$ ) fibres but because fibre typing in meat quality association studies had been almost exclusively based on histochemical methods, the changes in MyHC $2 b / 2 x$ fibres in the pig or MyHC $2 x$ fibres in cattle have not been determined. 
Calcineurin signals oxidative fibre type

Calcineurin (protein phosphatase 2B/PP2B) is an enzyme complex that comprises calcineurin $A(\mathrm{CnA})$ catalytic subunit, calcineurin $B(\mathrm{CnB})$ regulatory subunit and calciumbinding protein calmodulin (Schulz and Yutzey, 2004). It is a calcium dependent serine-threonine phosphatase that is widely distributed throughout the body. Calcineurin has been implicated in a wide variety of biological processes, including T-lymphocyte activation, vascular, neuronal and cardiac development and growth, and, more recently, skeletal muscle development (Crabtree, 2001; Bueno et al., 2002; Horsley and Pavlath, 2002). In cardiac muscle, calcineurin signalling is necessary for cardiomyocyte maturation, heart chamber formation and cardiac hypertrophy (Schulz and Yutzey, 2004). In skeletal muscle, calcineurin appears to be needed in a number of key developmental processes, namely enhanced muscle cell differentiation, and in the fibre type context, conversion to slow (oxidative) muscle phenotype (Musarò et al., 1999; Semsarian et al., 1999; Bigard et al., 2000; Delling et al., 2000). It has been reported that activated calcineurin mediates the hypertrophic effect of IGF-1 (Musarò et al., 1999; Semsarian et al., 1999). However, there is compelling evidence, including transgenic and knock-out data, to show that calcineurin has no effect on muscle hypertrophy but that the hypertrophic effect of IGF-1 is mediated by the PI3K pathway as detailed earlier (Naya et al., 2000; Bodine et al., 2001b; Rommel et al., 2001; Pallafacchina et al., 2002). Calcineurin is activated by raised intracellular calcium, triggered by extracellular signals like nervous impulses, or hormonal input, such as IGF-1 stimulation. To date, few substrates, namely NFATs, MEF2s and PGC- $1 \alpha$, of calcineurin action in skeletal muscle are known.

NFATs. The best characterised calcineurin substrates are members of the phosphorylated NFAT (nuclear factor of activated T-cells) family of transcription factors. Five NFAT genes, each with a distinct cellular role, have been identified: NFATc1 (NFAT2/NFATC), NFATC2 (NFATp/NFAT1), NFATc3 (NFAT4/NFATX), NFATc4 (NFAT3), and NFAT5 (Delling et al., 2000; Horsley and Pavlath, 2002). Several NFAT isoforms are expressed in skeletal muscle, each of which undergoes activation at specific stages of myogenesis. For instance, NFATc2 is activated only in new myotubes and plays a crucial role via IL-4 in mediating myoblast fusion (Horsley et al., 2003). Dephosphorylation of NFATs unmasks their nuclear localisation signal, resulting in nuclear translocation, where they bind to NFAT-binding sites on their own or as cooperative complexes with other factors, such as calcineurin, AP1, MEF2 and GATA2/4, to activate gene transcription (Musarò et al., 1999; Sugiura et al., 2001; Schulz and Yutzey, 2004). Cultured muscle fibres showed NFAT nuclear translocation only when electrically stimulated at a slow muscle pattern, which results in high intracellular calcium (100 to $300 \mathrm{nM}$ ) but not at a fast muscle pattern that results in low intracellular calcium
(<50 nM) (Liu et al., 2001; Fraysse et al., 2003). Nuclear NFATs are deactivated and re-located back to the cytoplasm through phosphorylation by several protein kinases, including GSK-3 $\beta$ (Figure 3), protein kinase A, p38 MAP kinase and casein kinase (Schulz and Yutzey, 2004). In T-cells, simultaneous activation of AP-1 (Jun/Fos) and NFAT is absolutely essential for cytokine transcriptional induction (Rao et al., 1997). In skeletal muscle, however, only GATA2 has been shown to be a co-operative binding partner of NFATs (Paul and Rosenthal, 2002).

MEF2s. Members of the MEF2 (myocyte enhancer-binding factor 2) family belong to a class of transcription factors that are responsible for the activation of many musclespecific genes with a conserved A/T-rich cis-acting regulatory element (Naya and Olson, 1999) and play a crucial role in p38 MAP kinase-mediated terminal muscle differentiation (discussed above). Like NFATs, MEF2 proteins form co-operative complexes with other factors, like members of the MyoD family, to regulate transcription. Calcineurin up-regulates the transcription of MEF2 genes (Wu et al., 2000a). It can also dephosphorylate MEF2 directly and enhance its transactivational activity (Dunn et al., 2001; Wu et al., 2001). Hence members of the MEF2 family are transcriptional targets and protein substrates of calcineurin.

PGC-1 $\alpha$. Peroxisome proliferator-activated receptor- $\gamma$ coactivator-1 (PPAR $\gamma$ co-activator $1 \alpha /$ PGC- $1 \alpha$ ), a ubiquitous transcriptional co-factor for nuclear receptors, is a potent inducer of mitochondrial biogenesis (Lin et al., 2002). It was recently shown to be able to convert fast fibres to the slow phenotype when over-expressed in transgenic mice. Part of this effect is thought to be mediated through the action of calcineurin on PGC- $1 \alpha$ as a substrate (see PPARs below) (Lin et al., 2002). As a co-factor, PGC-1 $\alpha$ is likely to exert its effects indirectly by modulating the expression of a specific group of downstream genes. Although all three substrates (NFATs, MEF2s and PGC-1 $\alpha$ ) are important mediators of calcineurin activation, none is exclusively expressed in skeletal muscle. Additional substrates not yet identified may well be involved in the signalling pathway. It is not known which regulatory target genes activated by NFAT, MEF- 2 or PGC- $1 \alpha$ are responsible for the phenotypic effects of calcineurin. Further work is needed to identify the genes regulated by the known and, possibly, other unidentified substrates of calcineurin.

Several endogenous calcineurin-specific inhibitors have been discovered. AKAP79, cain/cabin 1, and CBHP are ubiquitous factors and were found to inhibit NFAT function or translocation to the nucleus (Crabtree, 2001). More recently, two additional endogenous calcineurin-specific inhibitors (DSCR1/MCIP1 and ZAKI-4/DSCR1L1/MCIP2), highly expressed in striated muscles and brain, were found (Yang et al., 2000; Rothermel et al., 2001). DSCR1 expression is induced by calcineurin and hence forms a negative feedback loop to limit calcineurin activation 
(Yang et al., 2000). Its over-expression in transgenic mice prevented cardiac hypertrophy (Rothermel et al., 2001; Van Rooij et al., 2004). In skeletal muscle, the role of ZAKI-4 is particularly relevant because, unlike DSCR1, it is responsive to thyroid hormone stimulation (Cao et al., 2002). Thyroid hormone is a well known pleiotropic endocrine regulator of metabolism that modulates the transcription of a large number of genes, leading to increased metabolic rate, protein breakdown and muscle loss (Clement et al., 2002). The importance of thyroid hormone, however, on glucose and lipid homeostasis has not been addressed. In hyperthyroidism, muscle loss is accompanied by increase of fast fibres at the expense of slow fibres (Caiozzo et al., 1997). Triiodothyronine $\left(T_{3}\right)$ with clenbuterol greatly enhances the slow to fast fibre type switch (Awede et al., 2002). Such changes resemble the effects of chemical inhibitors of calcineurin, cyclosporine A or FK506, on muscle (Bueno et al., 2002). It is possible that the effects of thyroid hormone on muscle loss and fast phenotype conversion is mediated through the inhibition of calcinuerin by ZAKI-4.

There is little doubt that the calcineurin-NFAT pathway is critical in muscle phenotype determination, in particular its roles in muscle differentiation and slow fibre conversion. However, as in other pathways, calcineurin signalling is not an absolute effect in that it does not activate all slow genes in all muscles. Some fast muscle genes, like MyHC $2 b$ and SERCA1, are up-regulated in activated calcineurin transfected C2C12 cells (Swoap et al., 2000). Transgenic mice over-expressing the activated calcineurin in skeletal muscle showed substantial slow fibre switch but only in certain muscles (Naya et al., 2000).

\section{PPARs and PGC-1 $\alpha$ influence oxidative phenotype}

Peroxisome proliferator-activated receptors (PPAR) $\alpha, \gamma$ and $\delta / \beta$ belong to an important family of nuclear hormone receptors (transcription factors) that regulate genes that are involved in lipid metabolism (Muoio et al., 2002). PPAR $\alpha$, initially identified as the mediator of a class of compounds that induces peroxisomal proliferation in rodent liver, is most abundantly expressed in striated muscle (Muoio et al., 2002). Its activation increases fatty acid $\beta$ oxidation in muscle and reduces body weight (Koh et al., 2003). PPARy is more highly expressed in adipose tissues (Koh et al., 2003) and, in contrast to PPAR $\alpha$, stimulates adipocyte differentiation (Oberkofler et al., 2002; Yu et al., 2006). PPAR $\delta$ is highly expressed in adipose tissue, heart and skeletal muscle. Recently, it was shown that activated PPARס increases fatty acid oxidation in adipose tissue and muscle (Wang et al., 2003) and that during starvation its expression is up-regulated in skeletal muscle (Holst et al., 2003). PPAR $\alpha$, PPAR $\gamma$ and PPAR $\delta$ bind to the same consensus sequence, suggesting that mechanisms must exist that regulate PPAR type specificity (Oberkofler et al., 2002).

PPAR $\gamma$ co-activator $1 \alpha$ (PGC-1 $\alpha)$, cloned from a brown fat CDNA library for its interaction with PPAR $\gamma$, is a potent transcriptional activator that interacts with several nuclear hormone receptors, which include PPARs, steroid hormone receptors (glucocorticoid, oestrogen and mineralocorticoid), retinoic $X$ receptor, thyroid hormone receptor (Oberkofler et al., 2002), as well as MEF2 (Handschin et al., 2003). PGC- $1 \alpha$ stimulates mitochondrial function and number (biogenesis), and fatty acid oxidation in cardiac and skeletal muscles by the induction of mitochondrial and nuclear genes involved in energy production pathways, including PPAR $\alpha$ and nuclear respiratory factor-1 (NRF-1) (Miura et al., 2003). Therefore, the phenotypic effect of PGC-1 $\alpha$ activation, in partnership with nuclear hormone receptors, including PPARs, in skeletal muscle is increased oxidative capacity.

\section{Markers of atrophy and hypertrophy}

Markers of atrophy and hypertrophy are relevant to farm animal production from the perspective of disease and welfare. Animals suffer from a wide range of infectious and non-infectious diseases that are often manifested as reduced weight gain or net weight loss. Markers that can readily measure muscle atrophy or hypertrophy could have veterinary applications.

Biological markers that can predict the functional state of muscle are useful indicators in the diagnosis and monitoring of muscle conditions. Clearly, muscles that have undergone gross hypertrophy or atrophy would be apparent during examination. Muscles in the transitional process of remodelling are more difficult to recognise. Thus the use predictive biological markers would be valuable in identifying the underlying changes that are taking place in muscle.

E3 ubiquitin ligases as atrophic markers. Muscle atrophy is a consequence of a variety of conditions: denervation, injury, limb immobilisation, inactivity, glucocorticoid treatment, infection, diabetes, renal failure, cancer and ageing. In muscle atrophy, muscle loss is often the result of raised protein degradation and turn-over rather than simply due to reduced protein synthesis. Thus, atrophy is as much an active degradation process as a passive one from reduced stimulation of the anabolic (hyperplastic and hypertrophic) pathways. of the different protein degradation pathways (Costelli et al., 2003), the ATPdependent ubiquitin-proteasome proteolytic system is thought to be of major importance in skeletal muscle (Dehoux et al., 2003; Glass, 2003a). In this process, ubiquitin (Ub) is activated by an ubiquitin-activating enzyme (E1 family) and conjugated to a substrate protein by ubiquitin-conjugating enzyme (E2 family) in conjunction with ubiquitin protein ligase (E3 ligase family). E3 ligases, of which hundreds have been identified, confer substrate specificity (Glass, 2003a). During muscle atrophy, many of the genes encoding the Ub-proteasome pathway are upregulated (Lecker et al., 2004), including E2 (such as E2 $14 \mathrm{~K}$ and $\mathrm{UbcH} 2$ ) and E3 (such as E3 $\alpha$ / UBr1) genes (Li et al., 2003; Lecker et al., 2004). In particular, two E3 ubiquitin 
ligases, MuRF1 (muscle ring finger 1) and MAFbx (muscle atrophy F-box or atrogin-1) have been identified as mediators of muscle atrophy (Bodine et al., 2001a; Dehoux et al., 2003). MuRF1 and MAFbx are selectively induced in skeletal muscle and heart when subjected to a variety of atrophic conditions, such as denervation and glucocorticoid treatment. Their absence in null knock-out mice led to the preservation of muscle mass under atrophying conditions (Bodine et al., 2001a). TNF- $\alpha$ stimulated proteolysis may be mediated through the increased expression of MAFbx and MuRF1 (Dehoux et al., 2003; Glass 2005). MuRF1 contains three domains: a RING-finger domain, required for ubiquitin ligase activity, a B-box of unclear function, and a coil-coil domain, which may be required for heterodimerisation with a related protein MuRF2. Activation, by cachectic factors such as TNF $\alpha$, of the NF- $\kappa B$ transcription pathway induces skeletal muscle atrophy, which is mediated in part by NF- $\mathrm{KB}$ on the up-regulation of MuRF1 (Glass, 2005). MuRF1 physically interacts with titin, which suggests a possible role for MuRF1 in titin turn-over (Centner et al., 2001). MAFbx contains an F-box domain, characteristic of SCF family of E3 ubiquitin ligases. F-box E3 ligases usually bind post-translationally modified substrates, such as phosphorylation, and may target proteins involved in cell signalling. We recently found that in porcine congenital splayleg, a condition characterised with severe muscle weakness and fibre atrophy, MAFbx is abnormally up-regulated in relation to normal littermates (Ooi et al., 2006).

FOXO proteins, a subgroup of the Forkhead family of transcription factors, have been recently identified as mediators that link the signalling pathways of muscle hypertrophy and atrophy. FOXO transcription factors are important for the induction of cell quiescence and apoptosis. FOXO factors are targets of activated Akt (Figure 3). Direct and multiple phosphorylation by Akt on FOXO factors leads to their displacement from the nucleus to the cytoplasm and to the inhibition of their transcriptional activities (Burgering and Medema, 2004). Under atrophic conditions, FOXO1 (Stitt et al., 2004) and F0X03 (Sandri et al., 2004) have been shown to up-regulate the expression of MAFbx and MURF1. Inhibition of FOXO activity that leads to the down-regulation of $M A F b x$ and MURF1 is a necessary anti-atrophy step mediated by the PI3K-Akt1 pathway (Sandri et al., 2004; Stitt et al., 2004; Tesseraud et al., 2007). This anti-atrophy effect can be triggered by insulin as ligand which has the dual roles of enhancing protein synthesis (Figure 3 ) and decreasing proteolysis via FOXO inhibition (Tesseraud et al., 2007).

GATA-2 as a hypertrophic marker. Factors involved in signalling, muscle metabolism or sarcomeric structure that are associated with the process of muscle hypertrophy could potentially be used as hypertrophic markers. GATA-2 has been recently identified as a potentially useful candidate marker gene of muscle hypertrophy (Musarò et al., 1999; Paul and Rosenthal, 2002). In mammals, the GATA zinc-finger transcription factor family comprises six gene members that can be divided into 2 sub-groups, based on structure and function (LaVoie, 2003). GATA-1/2/-3 members are often associated with haematopoiesis and neural development. GATA-4/-5/-6 members are commonly associated with organ development, including heart, gut, blood vessels and parts of the genito-urinary system. With the exception of GATA-5, gene ablation of

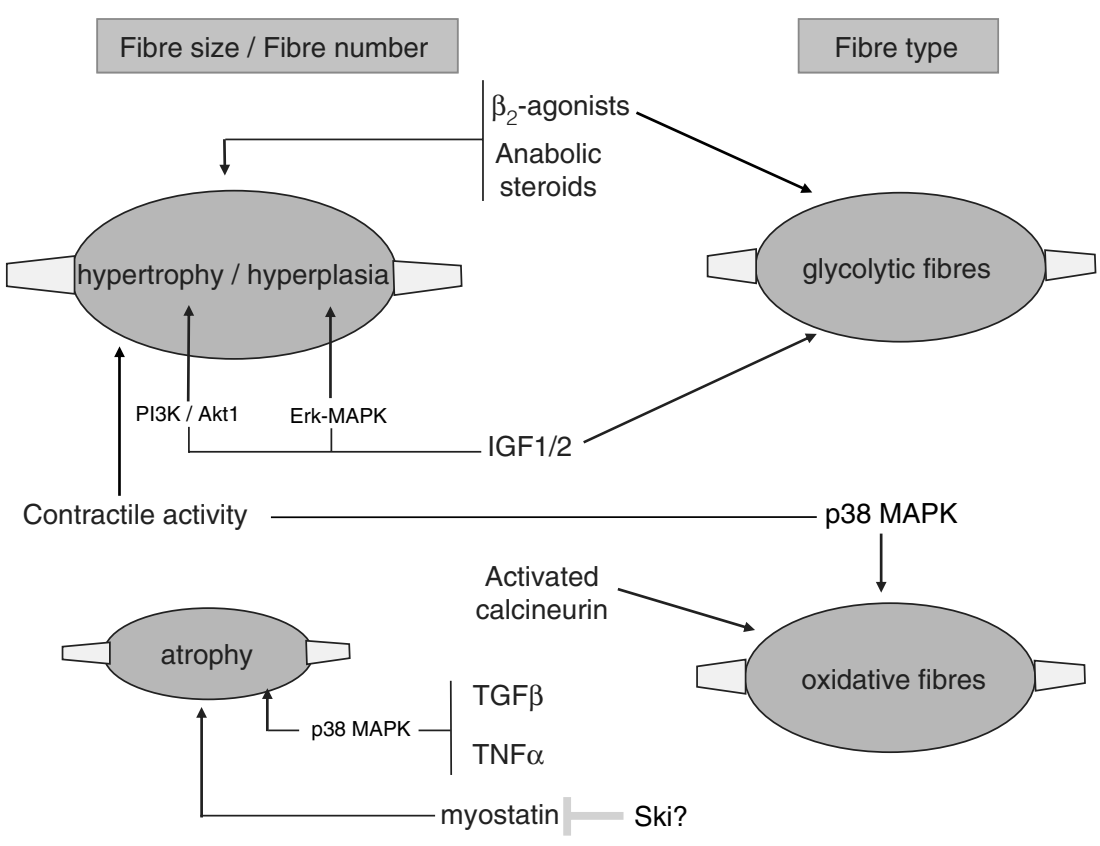

Figure 6 Summary actions of signalling factors and pathways on fibre size, fibre number and fibre types. p38 MAPK activation can result in a range of phenotypic outcome depending on the nature of activation. The proposed inhibition of myostatin by Ski has not been formally demonstrated. 
the GATA family members results in embryonic lethality. GATA-2 is necessary for mast cell development, and maintenance and expansion of multipotential progenitors and haematopoietic stem cells (Fujiwara et al., 2004). GATA-2 is usually absent or lowly expressed in skeletal muscle at all stages of development, but is induced in muscle cell culture and in vivo by IGF-1, during muscle regeneration after bupivacaine injection, and by exercise (Paul and Rosenthal, 2002; Sakuma et al., 2003). GATA-2 co-precipitates with calcineurin and NFATc1 (see below), suggesting it mediates its effect on muscle gene expression in conjunction with components of the calcineurin signalling pathway as a protein complex (Musarò et al., 1999; Sakuma et al., 2003). There is no direct evidence to show that GATA-2 is a hypertrophic factor, but its expression is closely associated with factors (e.g. IGF-1) and conditions (e.g. exercise, regeneration) that are involved in the process of hypertrophy and regeneration.

\section{Conclusion}

The determination of muscle phenotype (fibre number, size and fibre type) is highly complex and coordinated that requires the integration of several major signalling cascades (e.g. Erk-MAPK, p38 MAPK, PI3K-Akt and calcineurin signalling pathways), intracellular factors (transcription factors, like NFATs, and co-factors, such as PGC-1 $\alpha$ ) and extracellular factors (e.g. ligands, like myostatin and IGFs, and nutrition) (Figure 6). Enhanced hypertrophic growth, as exemplified in the pig, for greater lean meat production is associated with reduced intramuscular fat and increased accumulation of fast glycolytic fibres, the most common being the MyHC 2x and 2b fibres (Chang et al., 2003; Wood et al., 2004). Highly glycolytic fibres in the pig, however, are not conducive to the conferment of good meat quality traits, such as colour and water-holding capacity. In future farm animal production, improvements on meat quality could offer considerable economic attraction. At a fundamental level, one need is to discover key targets that mediate slow or oxidative fibre type switching. The recent introduction of the use of exon-expression arrays and ChIP-on-chip tiling arrays (Affymetrix) in functional genomics is likely to greatly accelerate our understanding of key molecular and signalling details in fibre phenotype determination. Identified target genes could be exploited through marker-assisted selection or by pharmacological / nutritional manipulation.

\section{References}

Adams GR 2002. Autocrine and/or paracrine insulin-like growth factor-I activity in skeletal muscle. Clinical Orthopaedics and Related Research 403S, S188-S196.

Akimoto T, Pohnert SC, Li P, Zhang M, Gumbs C, Rosenberg PB, Williams RS and Yan Z 2005. Exercise stimulates Pgc-1 $\alpha$ transcription in skeletal muscle through activation of the p38 MAPK pathway. Journal of Biological Chemistry 280, 19587-19593.
Artaza JN, Bhasin S, Magee TR, Reisz-Porszasz S, Shen R, Groome NP, Fareez MM and Gonzalez-Cadavid NF 2005. Myostatin inhibits myogenesis and promotes adipogenesis in $\mathrm{C} 3 \mathrm{H} \mathrm{10T(1/2)} \mathrm{mesenchymal} \mathrm{multipotent} \mathrm{cells.} \mathrm{Endocrin-}$ ology 146, 3547-3557.

Asakura A 2003. Stem cells in adult skeletal muscle. Trends in Cardiovascular Medicine 13, 123-128.

Awede BL, Thissen JP and Lebacq J 2002. Role of IGF-I and IGFBPs in the changes of mass and phenotype induced in rat soleus muscle by clenbuterol. AJP - Endocrinology and Metabolism 282, E31-E37.

Balasubramanian S and Kuppuswamy D 2003. RGD-containing peptides activate S6K1 through $\beta 3$ integrin in adult cardiac muscle cells. Journal of Biological Chemistry 278, 42214-42224.

Bancroft JD and Gamble M 2002. Theory and practice of histological techniques. Churchill Livingston, London.

Barton-Davis ER, Shoturma DI, Musaro A, Rosenthal N and Sweeney HL 1998. Viral mediated expression of insulin-like growth factor I blocks the agingrelated loss of skeletal muscle function. Proceedings of the National Academy of Sciences USA 95, 15603-15607.

Bass J, Oldham J, Sharma M and Kambadur R 1999. Growth factors controlling muscle development. Domestic Animal Endocrinology 17, 191-197.

Baxendale S, Davison C, Muxworthy C, Wolff C, Ingham W and Roy S 2004. The B-cell maturation factor Blimp-1 specifies vertebrate slow-twitch muscle fiber identity in response to Hedgehog signaling. Nature Genetics 36, 88-93.

Beuzen ND, Stear MJ and Chang KC 2000. Molecular markers and their use in animal breeding. Veterinary Journal 160, 42-52.

Bigard X, Sanchez H, Zoll J, Mateo P, Rousseau V, Veksler V and Ventura-Clapier R 2000. Calcineurin co-regulates contractile and metabolic components of slow muscle phenotype. Journal of Biological Chemistry 275, 19653-19660. Blanco A, Artacho-Perula E, Flores-Acuna R, Moyano R and Monterde JG 2003. Quantitative changes in the normal and apoptotic thymocytes of pigs treated with anabolic doses of the $\beta 2$ adrenergic agonist clenbuterol. Veterinary Immunology and Immunopathology 96, 111-115.

Blanco A, Flores-Acuna F, Roldan-Villalobos R and Monterde JG 2002. Testicular damage from anabolic treatments with the $\beta 2$-adrenergic agonist clenbuterol in pigs: a light and electron microscope study. Veterinary Journal 163, 292-298.

Bodine SC, Latres E, Baumhueter S, Lai VKM, Nunez L, Clarke BA, Poueymirou WT, Panaro FJ, Na E, Dharmarajan K, Pan Z-Q, Valenzuela DM, DeChiara TM, Stitt TN, Yancopoulos GD and Glass DJ 2001a. Identification of ubiquitin ligases required for skeletal muscle atrophy. Science 294, 1704-1708.

Bodine SC, Stitt TN, Gonzalez M, Kline WO, Stover GL, Bauerlein R, Zlotchenko E, Scrimgeour A, Lawrence JC, Glass DJ and Yancopoulos GD 2001b. Akt/mTOR pathway is a crucial regulator of skeletal muscle hypertrophy and can prevent muscle atrophy in vivo. Nature Cell Biology 3, 1014-1019.

Bouley J, Meunier B, Chambon C, De Smet S, Hocquette JF and Picard B 2006. Proteomic analysis of bovine skeletal muscle hypertrophy. Proteomics 5, 490500.

Brooke MH and Kaiser KK 1970. Muscle fiber types: how many and what kind? Archives of Neurology 23, 369-379.

Buckingham M 2001. Skeletal muscle formation in vertebrates. Current Opinion in Genetics \& Development 11, 440-448.

Buckingham M, Bajard L, Chang T, Daubas P, Hadchouel J, Meilhac S, Montarras $D$, Rocancourt $D$ and Relaix $F$ 2003. The formation of skeletal muscle: from somite to limb. Journal of Anatomy 202, 59-68.

Bueno OF, Van Rooij E, Molkentin JD, Doevendans PA and De Windt LJ 2002. Calcium and hypertrophic heart disease: novel insights and remaining questions. Cardiovascular Research 53, 806-821.

Burgering BMT and Medema RH 2004. Decisions on life and death: FOXO forkhead transcription factors are in command when PKB/Akt is off duty. Journal of Leukocyte Biology 73, 689-701.

Burniston JG, Ng Y, Clark WA, Colyer J, Tan LB and Goldspink DF 2002. Myotoxic effects of clenbuterol in the rat heart and soleus muscle. Journal of Applied Physiology 93, 1824-1832.

Byrne KA, Wang YH, Lehnert SA, Harper GS, McWilliam SM, Bruce HL and Reverter A 2005. Gene expression profiling of muscle tissue in Brahman steers during nutritional restriction. Journal of Animal Science 83, 1-12.

Cabane C, Englaro W, Yeow K, Ragno M and Derijard B 2003. Regulation of C2C12 myogenic terminal differentiation by MKK3/p38 $\alpha$ pathway. American Journal of Physiology -Cell Physiology 284, C658-C666. 
Caiozzo VJ 2004. Plasticity of skeletal muscle phenotype: mechanical consequences. Muscle Nerve 26, 740-768.

Caiozzo VJ, Baker MJ, McCue SA and Baldwin KM 1997. Single-fiber and whole muscle analyses of MHC isoform plasticity: interaction between T3 and unloading. American Journal of Physiology -Cell Physiology 273, C944C952.

Cao X, Kambe F, Miyazaki T, Sarkar D, Ohmori S and Seo H 2002. Novel human ZAKI-4 isoforms: hormonal and tissue-specific regulation and function as calcineurin inhibitors. Biochemical Journal 367, 459-466.

Casser-Malek I, Hocquette JF, Jurie C, Listrat A, Jailler R, Bauchart D, Briand Y and Picard B 2004. Muscle-specific metabolic, histochemical and biochemical responses to a nutritionally induced discontinuous growth path. Animal Science 79, 49-59.

Centner T, Yano J, Kimura E, McElhinny AS, Pelin K, Witt CC, Bang ML, Trombitas K, Granzier H and Gregorio CC 2001. Identification of muscle specific ring finger proteins as potential regulators of the titin kinase domain. Journal of Molecular Biology 306, 717-726.

Chang KC, Da Costa N, Blackley R, Southwood O, Evans G, Plastow G, Wood JD and Richardson RI 2003. Relationships of myosin heavy chain fibre types to meat quality traits in traditional and modern pigs. Meat Science 64, 93-103.

Chang KC and Fernandes K 1997. Developmental expression and $5^{\prime}$ end CDNA cloning of the porcine $2 x$ and $2 b$ myosin heavy chain genes. DNA and Cell Biology 16, 1429-1437.

Chang KC, Fernandes K and Dauncey MJ 1995. Molecular characterization of a developmentally regulated porcine skeletal myosin heavy chain gene and its $5^{\prime}$ regulatory region. Journal of Cell Science 108, 1779-1789.

Chang KC, Fernandes K and Goldspink G 1993. In vivo expression and molecular characterization of the porcine slow-myosin heavy chain. Journal of Cell Science 106, 331-341.

Charge SBP, Brack AS and Hughes SM 2002. Aging-related satellite cell differentiation defect occurs prematurely after Ski-induced muscle hypertrophy. American Journal of Physiology -Cell Physiology 283, C1228-C1241.

Chen Y, Zajac JD and MacLean HE 2005. Androgen regulation of satellite cell function. Journal of Endocrinology 186, 21-31.

Chikuni K, Muroya S and Nakajima I 2004. Absence of the functional myosin heavy chain $2 \mathrm{~b}$ isoform in equine skeletal muscles. Zoological Science 21 , 589-596.

Clement K, Viguerie N, Diehn M, Alizadeh A, Barbe P, Thalamas C, Storey JD, Brown PO, Barsh GS and Langin D 2002. In vivo regulation of human skeletal muscle gene expression by thyroid hormone. Genome Research 12, 281-291.

Conejo R, Valverde AM, Benito $M$ and Lorenzo M 2001. Insulin produces myogenesis in $\mathrm{C} 2 \mathrm{C} 12$ myoblasts by induction of NF- $\mathrm{KB}$ and downregulation of AP-1 activities. Journal of Cellular Physiology 186, 82-94.

Coolican SA, Samuel DS, Ewton DZ and McWade FJ 1997. The mitogenic and myogenic actions of insulin-like growth factors utilize distinct signaling pathways. Journal of Biological Chemistry 272, 6653-6662.

Costelli P, Carbo N, Busquets S, Lopez-Soriano FJ, Baccino FM and Argiles JM 2003. Reduced protein degradation rates and low expression of proteolytic systems support skeletal muscle hypertrophy in transgenic mice overexpressing the c-ski oncogene. Cancer Letters 200, 153-160.

Crabtree GR 2001. Calcium, calcineurin, and the control of transcription. Journal of Biological Chemistry 276, 2313-2316.

Da Costa N, McGillivray C, Bai Q, Wood JD, Evans G and Chang KC 2004. Energy and protein restriction induces molecular changes in young porcine skeletal muscles. Journal of Nutrition 134, 2191-2199.

Da Costa N, McGillivray C and Chang KC 2003. Postnatal myosin heavy chain isoforms in prenatal porcine skeletal muscles: insights into temporal regulation. Anatomical Record 273A 731-740.

Dehoux MJM, Van Beneden RP, Fernandez-Celemin L, Lause PL and Thissen JP 2003. Induction of MafBx and Murf ubiquitin ligase mRNAs in rat skeletal muscle after LPS injection. FEBS Letters 544, 214-217.

Delling U, Tureckova J, Lim HW, De Windt LJ, Rotwein P and Molkentin JD 2000. A calcineurin-NFATc3-dependent pathway regulates skeletal muscle differentiation and slow myosin heavy-chain expression. Molecular and Cellular Biology 20, 6600-6611.

Denley A, Cosgrove LJ, Booker GW, Wallace JC and Forbes BE 2005. Molecular interactions of the IGF system. Cytokine \& Growth Factor Reviews 16, 421-439.
Doumit ME, Cook DR and Merkel RA 1996. Testosterone up-regulates androgen receptors and decreases differentiation of porcine myogenic satellite cells in-vitro. Endocrinology 137, 1385-1394.

Du M, Zhu MJ, Means WJ, Hess BW and Ford SP 2005. Nutrient restriction differentially modulates the mammalian target of rapamycin signaling and the ubiquitin-proteasome system in skeletal muscle of cows and their fetuses. Journal of Animal Science 83, 117-123.

Dunn SE, Simard AR, Bassel-Duby R, Williams RS and Michel RN 2001. Nerve activity-dependent modulation of calcineurin signaling in adult fast and slow skeletal muscle fibers. Journal of Biological Chemistry 276, 45243-45254.

Dunshea FR, D'Souza DN, Pethick DW, Harper GS and Warner RD 2005. Effects of dietary factors and other metabolic modifiers on quality and nutritional value of meat. Meat Science 71, 8-38.

Dwyer CM, Stickland NC and Fletcher JM 1994. The influence of maternal nutrition on muscle fiber number development in the porcine fetus and on subsequent postnatal growth. Journal of Animal Science 72, 911-917.

Erbay $\mathrm{E}$ and Chen $\mathrm{J}$ 2001. The mammalian target of rapamycin regulates C2C12 myogenesis via a kinase-independent mechanism. Journal of Biological Chemistry 276, 36079-36082.

Erbay E, Park IH, Nuzzi PD, Schoenherr CJ and Chen J 2003. IGF-II transcription in skeletal myogenesis is controlled by mTOR and nutrients. Journal of Cell Biology 163, 931-936.

Espinosa L, Ingles-Esteve J, Aguilera C and Bigas A 2003. Phosphorylation by glycogen synthase kinase-3 $\beta$ down-regulates notch activity, a link for notch and Wnt pathways. Journal of Biological Chemistry 278, 32227-32235.

Essén-Gustavsson B 1993. Muscle-fiber characteristics in pigs and relationships to meat-quality parameters- review. In Pork quality: genetic and metabolic factors (ed. E Puolanne and DI Demeyer), pp. 140-159, CAB International, Wallingford UK.

Fang SH, Nishimura T and Takahashi K 1999. Relationship between development and intramuscular connective tissue and toughness of pork during growth of pigs. Journal of Animal Science 77, 120-130.

Fraysse B, Desaphy JF, Pierno S, De Luca A, Liantonio A, Mitolo $\mathrm{Cl}$ and Camerino DC 2003. Decrease in resting calcium and calcium entry associated with slow-to-fast transition in unloaded rat soleus muscle. FASEB Journal 17, 1916-1918.

Fujiwara Y, Chang AN, Williams AM and Orkin SH 2004. Functional overlap of GATA-1 and GATA-2 in primitive hematopoietic development. Blood 103, 583-585.

Geay Y, Bauchart D, Hocquette J-F and Culioli J 2001. Effect of nutritional factors on biochemical, structural and metabolic characteristics of muscles in ruminants, consequences on dietetic value and sensorial qualities of meat. Reproduction Nutrition Development 41, 1-26.

Gil F, Lopez-Albors 0, Vazquez JM, Latorre R, Ramirez-Zarzosa G and Moreno F 2001. The histochemical profiles of fibre types in porcine skeletal muscle. Histology and Histopathology 16, 439-442.

Giles RH, Van Es JH and Clevers H 2003. Caught up in a Wnt storm: Wnt signaling in cancer. Biochimica et Biophysica Acta -Reviews on Cancer 1653, 1-24.

Glass DJ 2003a. Molecular mechanisms modulating muscle mass. Trends in Molecular Medicine 9, 344-350.

Glass DJ 2003b. Signalling pathways that mediate skeletal muscle hypertrophy and atrophy. Nature Cell Biology 5, 87-90.

Glass DJ 2005. Skeletal muscle hypertrophy and atrophy signaling pathways. International Journal of Biochemistry \& Cell Biology 37, 1974-1984.

Goldring K, Partridge T and Watt D 2002. Muscle stem cells. Journal of Pathology 197, 457-467.

Grobet L, Martin LJR, Poncelet D, Pirottin D, Brouwers B, Riquet J, Schoeberlein A, Dunner S, Ménissier F, Massabanda J, Fries R, Hanset R and Georges M 1997. A deletion in the bovine myostatin gene causes the double-muscled phenotype in cattle. Nature Genetics 17, 71-74.

Haddad F and Adams GR 2004. Inhibition of MAP/ERK kinase prevents IGF-I induced hypertrophy in rat muscles. Journal of Applied Physiology 96, 203-210. Hallauer PL and Hastings KEM 2002. Coregulation of fast contractile protein transgene and glycolytic enzyme expression in mouse skeletal muscle. American Journal of Physiology -Cell Physiology 282, C113-C124.

Handschin C, Rhee J, Lin J, Tarr PT and Spiegelman BM 2003. An autoregulatory loop controls peroxisome proliferator-activated receptor $\gamma$ coactivator $1 \alpha$ 
expression in muscle. Proceedings of the National Academy of Sciences USA 100, 7111-7116.

Hinkle RT, Hodge KMB, Cody DB, Sheldon RJ, Kobilka BK and Isfort RJ 2002. Skeletal muscle hypertrophy and anti-atrophy effects of clenbuterol are mediated by the $\beta 2$-adrenergic receptor. Muscle Nerve 25, 729-734.

Hirai S, Matsumoto H, Hino N, Kawachi H, Matsui T and Yano H 2007. Myostatin inhibits differentiation of bovine preadipocyte. Domestic Animal Endocrinology 32, 1-14.

Hocquette JF, Ortigues-Marty I, Pethick D, Herpin P and Fernandez X 1998. Nutritional and hormonal regulation of energy metabolism in skeletal muscles of meat-producing animals. Livestock Production Science 56, 115-143.

Holst $D$, Luquet $S$, Nogueira V, Kristiansen $K$, Leverve $X$ and Grimaldi PA 2003. Nutritional regulation and role of peroxisome proliferator-activated receptor $\delta$ in fatty acid catabolism in skeletal muscle. Biochimica et Biophysica Acta 1633, 43-50.

Hornick JL, Van Eenaeme C, Gérard O, Dufrasne I and Istasse L 2000. Mechanisms of reduced and compensatory growth. Domestic Animal Endocrinology 19, 121-132.

Horsley V, Jansen KM, Mills ST and Pavlath GK 2003. IL-4 acts as a myoblast recruitment factor during mammalian muscle growth. Cell 113, 483-494.

Horsley V and Pavlath GK 2002. NFAT: ubiquitous regulator of cell differentiation and adaptation. Journal of Cell Biology 156, 771-774.

Ji SQ, Losinski RL, Cornelius SG, Frank GR, Willis GM, Gerrard DE, Depreux FS and Spurlock ME 1998. Myostatin expression in porcine tissues: tissue specificity and developmental and postnatal regulation. American Journal of Physiology -Regulatory Integrative and Comparative Physiology 44, R1265-R1273.

Jiang BH, Zheng JZ and Vogt PK 1998. An essential role of phosphatidylinositol 3-kinase in myogenic differentiation. Proceedings of the National Academy of Sciences USA 95, 14179-14183.

Jope RS 2003. Lithium and GSK-3: one inhibitor, two inhibitory actions, multiple outcomes. Trends in Pharmacological Sciences 24, 441-443.

Kamanga-Sollo E, Pampusch MS, White ME and Dayton WR 2003. Role of insulin-like growth factor binding protein (IGFBP)-3 in TGF- $\beta$ and GDF-8 (myostatin)-induced suppression of proliferation in porcine embryonic myogenic cell cultures. Journal of Cellular Physiology 197, 225-231.

Kambadur R, Sharma M, Smith TL and Bass JJ 1997. Mutations in myostatin (GDF8) in double-muscled Belgian blue and Piedmontese cattle. Genome Research 7, 910-916.

Karlsson AH, Klont RE and Fernandez X 1999. Skeletal muscle fibres as factors for pork quality. Livestock Production Science 60, 255-269.

Kelley DE, Goodpaster BH and Storlien L 2002. Muscle triglyceride and insulin resistance. Annual Review of Nutrition 22, 325-346.

Kirk SP, Oldham JM, Jeanplong F and Bass JJ 2003. Insulin-like growth factorII delays early but enhances late regeneration of skeletal muscle. Journal of Histochemistry and Cytochemistry 51, 1611-1620.

Klont RE, Brocks L and Eikelenboom G 1998. Muscle fibre type and meat quality. Meat Science 49, S219-S229.

Kocamis $\mathrm{H}$ and Killefer $\mathrm{J}$ 2002. Myostatin expression and possible functions in animal muscle growth. Domestic Animal Endocrinology 23, 447-454.

Koh EH, Kim M-S, Park J-T, Kim HS, Youn J-Y, Park H-S, Youn JH and Lee K-U 2003. Peroxisome proliferator-activated receptor (PPAR)- $\alpha$ activation prevents diabetes in OLETF rats: comparison with PPAR- $\gamma$ activation. Diabetes 52, 2331-2337.

Kutscher EC, Luna BC and Perry PJ 2002. Anabolic steroids: a review for the clinician. Sports Medicine 32, 285-296.

Langley B, Thomas M, Bishop A, Sharma M, Gilmour S and Kambadur R 2002. Myostatin inhibits myoblast differentiation by down-regulating MyoD expression. Journal of Biological Chemistry 277, 49831-49840.

LaVoie HA 2003. The role of GATA in mammalian reproduction. Experimental Biology and Medicine 228, 1282-1290.

Lecker SH, Jagoe RT, Gilbert A, Gomes M, Baracos V, Bailey J, Price SR, Mitch WE and Goldberg AL 2004. Multiple types of skeletal muscle atrophy involve a common program of changes in gene expression. FASEB Journal 18, 39-51.

Lee J, Hong F, Kwon S, Kim SS, Ki DO, Kang HS, Lee SJ, Ha J and Kim SS 2002. Activation of p38 MAPK induces cell cycle arrest via inhibition of Raf/ ERK pathway during muscle differentiation. Biochemical and Biophysical Research Communications 298, 765-771.
Lefaucheur L, Milan D, Eolan P and Le Callennec C 2004. Myosin heavy chain composition of different skeletal muscles in Large White and Meishan pigs. Journal of Animal Science 82, 1931-1941.

Li YP, Chen Y, John J, Moylan J, Jin B, Mann DL and Reid MB 2005. TNF- $\alpha$ acts via $\mathrm{p} 38$ MAPK to stimulate expression of the ubiquitin ligase atrogin1/ MAFbx in skeletal muscle. FASEB Journal 19, 362-370.

Li YP, Chen Y, Li AS and Reid MB 2003. Hydrogen peroxide stimulates ubiquitin-conjugating activity and expression of genes for specific E2 and E3 proteins in skeletal muscle myotubes. American Journal of Physiology -Cell Physiology 285, C806-C812.

Lin J, Wu H, Tarr PT, Zhang CY, Wu Z, Boss O, Michael LF, Puigserver P, Isotani E, Olson EN, Lowell BB, Bassel-Duby R and Spiegelman BM 2002. Transcriptional co-activator PGC-1 $\alpha$ drives the formation of slow-twitch muscle fibres. Nature 418, 797-801.

Liu W, Thomas SG, Asa SL, Gonzalez-Cadavid N, Bhasin S and Ezzat S 2003. Myostatin is a skeletal muscle target of growth hormone anabolic action. Journal of Clinical Endocrinology and Metabolism 88, 5490-5496.

Liu Y, Cseresnyés Z, Randall WR and Schneider MF 2001. Activity-dependent nuclear translocation and intranuclear distribution of NFATc in adult skeletal muscle fibers. Journal of Cell Biology 155, 27-40.

Lynch GS, Cuffe SA, Plant DR and Gregorevic P 2001. IGF-I treatment improves the functional properties of fast- and slow-twitch skeletal muscles from dystrophic mice. Neuromuscular Disorders 11, 260-268.

Maak S, Jaesert S, Neumann K, Yerle M and Von Lengerken G 2001. Isolation of expressed sequence tags of skeletal muscle of neonatal healthy and splay leg piglets and mapping by somatic cell hybrid analysis. Animal Genetics 32, 303-307.

MacAulay K, Hajduch E, Blair AS, Coghlan MP, Smith SA and Hundal HS 2003. Use of lithium and SB-415286 to explore the role of glycogen synthase kinase-3 in the regulation of glucose transport and glycogen synthase. European Journal of Biochemistry 270, 3829-3838.

McCormick RJ 1999. Extracellular modifications to muscle collagen: implications for meat quality. Poultry Science 78, 785-791.

McCroskery S, Thomas M, Maxwell L, Sharma M and Kambadur R 2003. Myostatin negatively regulates satellite cell activation and self-renewal. Journal of Cell Biology 162, 1135-1147.

McPherron AC and Lee SJ 1997. Double muscling in cattle due to mutations in the myostatin gene. Proceedings of the National Academy of Sciences USA 94, 12457-12461.

Maccatrozzo L, Patruno M, Toniolo L, Reggiani C and Mascarello F 2004. Myosin heavy chain 2B isoform is expressed in specialized eye muscles but not in trunk and limb muscles of cattle. European Journal of Histochemistry 48, 357-366.

Maltin C, Balcerzak D, Tilley R and Delday M 2003. Determinants of meat quality: tenderness. Proceedings of the Nutrition Society 62, 337-347.

Marchitelli C, Savarese MC, Crisa A, Nardone A, Marsan PA and Valentini A 2003. Double muscling in Marchigiana beef breed is caused by a stop codon in the third exon of myostatin gene. Mammalian Genome 14, 392-395.

Martin B, Schneider R, Janetzky S, Waibler Z, Pandur P, Kuhl M, Behrens J, der Mark K, Starzinski-Powitz A and Wixler V 2002. The LIM-only protein FHL2 interacts with $\beta$-catenin and promotes differentiation of mouse myoblasts. Journal of Cell Biology 159, 113-122.

Masuda ES, Imamura R, Amasaki Y, Arai K and Arai N 1998. Signalling into the T-cell nucleus: NFAT regulation. Cellular Signalling 10, 599-611.

Mersmann HJ 1998. Overview of the effects of $\beta$-adrenergic receptor agonists on animal growth including mechanisms of action. Journal of Animal Science 76, 160-172.

Mills SE, Spurlock ME and Smith DJ 2003. $\beta$-Adrenergic receptor subtypes that mediate ractopamine stimulation of lipolysis. Journal of Animal Science 81, 662-668.

Mitin N, Kudla AJ, Konieczny SF and Taparowsky EJ 2001. Differential effects of Ras signaling through NFKB on myogenesis. Oncogene 20, 1276-1286.

Miura S, Kai Y, Ono M and Ezaki 0 2003. Overexpression of peroxisome proliferator-activated receptor $\gamma$ coactivator- $1 \alpha$ down-regulates GLUT4 mRNA in skeletal muscles. Journal of Biological Chemistry 278, 31385-31390.

Morali OG, Jouneau A, McLaughlin KJ, Thiery JP and Larue L 2000. IGFII promotes mesoderm formation. Developmental Biology 227, 133-145. 
Morio B, Hocquette JF, Montaurier C, Boirie Y, Bouteloup-Demange C, McCormack C, Fellmann N, Beaufrere B and Ritz P 2001. Muscle fatty acid oxidative capacity is a determinant of whole body fat oxidation in elderly people. American Journal of Physiology - Endocrinology and Metabolism 280, E143-E149.

Muoio DM, Way JM, Tanner CJ, Winegar DA, Kliewer SA, Houmard JA, Kraus WE and Dohm GL 2002. Peroxisome proliferator-activated receptor- $\alpha$ regulates fatty acid utilization in primary human skeletal muscle cells. Diabetes 51, 901-909.

Murgia M, Serrano AL, Calabria E, Pallafacchina G, Lømo T and Schiaffino S 2000. Ras is involved in nerve-activity-dependent regulation of muscle genes. Nature Cell Biology 2, 142-147.

Musarò A, McCullagh JA, Naya FJ, Olson EN and Rosenthal N 1999. IGF-1 induces skeletal myocyte hypertrophy through calcineurin in association with GATA-2 and NF-ATc1. Nature 400, 581-585.

Musarò A, McCullagh K, Paul A, Houghton L, Dobrowolny G, Molinaro M, Barton ER, Sweeney HL and Rosenthal N 2001. Localized Igf-1 transgene expression sustains hypertrophy and regeneration in senescent skeletal muscle. Nature Genetics 27, 195-200.

Naya FJ, Mercer B, Shelton J, Richardson JA, Williams RS and Olson EN 2000. Stimulation of slow skeletal muscle fiber gene expression by calcineurin in vivo. Journal of Biological Chemistry 275, 4545-4548.

Naya FJ and Olson E 1999. MEF2: a transcriptional target for signaling pathways controlling skeletal muscle growth and differentiation. Current Opinion in Cell Biology 11, 683-688.

Nissen PM, Danielsen VO, Jorgensen PF and Oksbjerg N 2003. Increased maternal nutrition of sows has no beneficial effects on muscle fiber number or postnatal growth and has no impact on the meat quality of the offspring. Journal of Animal Science 81, 3018-3027.

Novak A and Dedhar S 1999. Signaling through $\beta$-catenin and Lef/Tcf. Cellular and Molecular Life Sciences 56, 523-537.

Oberkofler $\mathrm{H}$, Esterbauer $\mathrm{H}$, Linnemayr V, Strosberg AD, Krempler $\mathrm{F}$ and Patsch $W$ 2002. Peroxisome proliferator-activated receptor (PPAR) $\gamma$ coactivator-1 recruitment regulates PPAR subtype specificity. Journal of Biological Chemistry 277, 16750-16757.

Oka A, Iwaki F, Dohgo T, Ohtagaki S, Noda M, Shiozaki T, Endoh 0 and Ozaki M 2002. Genetic effects on fatty acid composition of carcass fat of Japanese Black Wagyu steers. Journal of Animal Science 80, 1005-1011.

Ooi PT, Da Costa N, Edgar J and Chang KC 2006. Porcine congenital splayleg is characterised by muscle fibre atrophy associated with relative rise in MAFbx and fall in P311 expression. BMC Veterinary Research 2, 23.

Pallafacchina G, Calabria E, Serrano AL, Kalhovde JM and Schiaffino S 2002. A protein kinase B-dependent and rapamycin-sensitive pathway controls skeletal muscle growth but not fiber type specification. Proceedings of the National Academy of Sciences USA 99, 9213-9218.

Parkington JD, Siebert AP, LeBrasseur NK and Fielding RA 2003. Differential activation of mTOR signaling by contractile activity in skeletal muscle. American Journal of Physiology -Regulatory Integrative and Comparative Physiology 285, R1086-R1090.

Paul AC and Rosenthal N 2002. Different modes of hypertrophy in skeletal muscle fibers. Journal of Cell Biology 156, 751-760.

Petropoulos $\mathrm{H}$ and Skerjanc IS 2002. $\beta$-Catenin is essential and sufficient for skeletal myogenesis in P19 Cells. Journal of Biological Chemistry 277, 15393-15399.

Pette D and Staron RS 2000. Myosins isoforms, muscle fiber types, and transitions. Microscopy Research and Technique 50, 500-509.

Philip B, Lu Z and Gao Y 2005. Regulation of GDF-8 signaling by the p38 MAPK. Cellular Signalling 17, 365-375.

Picard B, Gagniere H, Geay Y, Hocquette J-F and Robelin J 1995. Study of the influence of age and weaning on the contractile and metabolic characteristics of bovine muscle. Reproduction Nutrition Development 35, 71-84.

Picard B, Lefaucheur L, Berri C and Duclos MJ 2002. Muscle fibre ontogenesis in farm animal species. Reproduction Nutrition Development 42, 415-431.

Polesskaya A, Seale P and Rudnicki MA 2003. Wnt signaling induces the myogenic specification of resident CD45 + adult stem cells during muscle regeneration. Cell 113, 841-852.

Prunier C, Pessah M, Ferrand N, Seo SR, Howe P and Atfi A 2003. The oncoprotein Ski acts as an antagonist of transforming growth factor- $\beta$ signaling by suppressing Smad2 phosphorylation. Journal of Biological Chemistry 278, 26249-26257.
Rao A, Luo C and Hogan PG 1997. Transcription factors of the NFAT family:regulation and function. Annual Review of Immunology 15, 707-747.

Rehfeldt C, Kuhn G, Vanselow J, Fürbass R, Fiedler I, Nürnberg G, Clelland AK, Stickland NC and Ender K 2001. Maternal treatment with somatotropin during early gestation affects basic events of myogenesis in pigs. Cell and Tissue Research 306, 429-440.

Relaix F 2006. Skeletal muscle progenitor cells: from embryo to adult. Cellular and Molecular Life Sciences 63, 1221-1225.

Rommel C, Bodine SC, Clarke BA, Rossman R, Nunez L, Stitt TN, Yancopoulos GD and Glass DJ 2001. Mediation of IGF-1-induced skeletal myotube hypertrophy by $\mathrm{PI}(3) \mathrm{K} / \mathrm{Akt} / \mathrm{mTOR}$ and $\mathrm{PI}(3) \mathrm{K} / \mathrm{Akt} / \mathrm{GSK} 3$ pathways. Nature Cell Biology 3, 1009-1013.

Rommel C, Clarke BA, Zimmermann S, Nuñez L, Rossman R, Reid K, Moelling K, Yancopoulos GD and Glass DJ 1999. Differentiation stage-specific inhibition of the Raf-MEK-ERK pathway by Akt. Science 286, 1738-1744.

Rothermel BA, McKinsey TA, Vega RB, Nicol RL, Mammen P, Yang J, Antos CL, Shelton JM, Bassel-Duby R, Olson EN and Williams RS 2001. Myocyteenriched calcineurin-interacting protein, MCIP1, inhibits cardiac hypertrophy in vivo. Proceedings of the National Academy of Sciences USA 98, 3328-3333.

Ryall JG, Gregorevic P, Plant DR, Sillence MN and Lynch GS 2002. $\beta 2$-Agonist fenoterol has greater effects on contractile function of rat skeletal muscles than clenbuterol. American Journal of Physiology -Regulatory Integrative and Comparative Physiology 283, R1386-R1394.

Sakamoto K, Aschenbach WG, Hirshman MF and Goodyear LJ 2003. Akt signaling in skeletal muscle: regulation by exercise and passive stretch. American Journal of Physiology - Endocrinology and Metabolism 285, E1081-E1088.

Sakuma K, Nishikawa J, Nakao R, Watanabe K, Totsuka T, Nakano H, Sano M and Yasuhara M 2003. Calcineurin is a potent regulator for skeletal muscle regeneration by association with NFATc1 and GATA-2. Acta Neuropathologica 105, 271-280.

Sandri M, Sandri C, Gilbert A, Skurk C, Calabria E, Picard A, Walsh K, Schiaffino S, Lecker SH and Goldberg AL 2004. Foxo transcription factors induce the atrophy-related ubiquitin ligase atrogin-1 and cause skeletal atrophy. Cell 117, 399-412.

Sant'ana Pereira JA, Wessels A, Nijtmans L, Moorman AF and Sargeant AJ 1995. New method for the accurate characterization of single human skeletal muscle fibres demonstrates a relation between mATPase and MyHC expression in pure and hybrid fibre types. Journal of Muscle Research and Cell Motility 16, 21-34.

Schiaffino S and Reggiani C 1996. Molecular diversity of myofibrillar proteins: gene regulation and functional significance. Physiological Reviews 76, 371423.

Schiaffino S and Reggiani C 1994. Myosin isoforms in mammalian skeletal muscle. Journal of Applied Physiology 77, 493-501.

Schulz RA and Yutzey KE 2004. Calcineurin signaling and NFAT activation in cardiovascular and skeletal muscle development. Developmental Biology 266, 1-16.

Semsarian C, Wu MJ, Ju YK, Marcinec T, Yeoh T, Allen DG, Harvey RP and Graham RM 1999. Skeletal muscle hypertrophy is mediated by a $\mathrm{Ca}^{2+}$-dependent calcineurin signalling pathway. Nature 400, 576-581.

Shi DL, Bourdelas A, Umbhauer M and Boucaut JC 2002. Zygotic Wnt/ $\beta$-catenin signaling preferentially regulates the expression of Myf5 gene in the mesoderm of xenopus. Developmental Biology 245, 124-135.

Sillence MN, Munn KJ and Campbell RG 2002. Manipulation of growth in pigs through treatment of the neonate with clenbuterol and somatotropin. Journal of Animal Science 80, 1852-1862.

Sinha-Hikim I, Roth SM, Lee MI and Bhasin S 2003. Testosterone-induced muscle hypertrophy is associated with an increase in satellite cell number in healthy, young men. American Journal of Physiology - Endocrinology and Metabolism 285, E197-E205.

Soeta C, Suzuki M, Suzuki S, Naito K, Tachi C and Tojo H 2001. Possible role for the c-ski gene in the proliferation of myogenic cells in regenerating skeletal muscles of rats. Development Growth and Differentiation 43, 155-164.

Spangenburg EE and Booth FW 2003. Molecular regulation of individual skeletal muscle fibre types. Acta Physiologica Scandinavica 178, 413-424.

Steelman CA, Recknor JC, Nettleton D and Reecy JM 2006. Transcriptional profiling of myostatin-knockout mice implicates Wnt signaling in postnatal skeletal muscle growth and hypertrophy. FASEB Journal 20, 580-582. 
Stitt TN, Drujan D, Clarke BA, Panaro F, Timofeyva Y, Kline WO, Gonzalez M, Yancopoulos GD and Glass DJ 2004. The IGF-1/PI3K/Akt pathway prevents expression of muscle atrophy-induced ubiquitin ligases by inhibiting FOXO transcription factors. Molecular Cell 14, 395-403.

Sugiura T, Sio SO, Shuntoh H and Kuno T 2001. Molecular genetic analysis of the calcineurin signaling pathways. Cellular and Molecular Life Sciences 58, 278-288.

Sutrave P, Kelly AM and Hughes SH 1990. Ski can cause selective growth of skeletal muscle in transgenic mice. Genes and Development 4, 1462-1472.

Sutrave P, Leferovich JM, Kelly AM and Hughes SH 2000. The induction of skeletal muscle hypertrophy by a ski transgene is promoter-dependent. Gene 241, 107-116.

Swoap SJ, Hunter RB, Stevenson EJ, Felton HM, Kansagra NV, Lang JM, Esser KA and Kandarian SC 2000. The calcineurin-NFAT pathway and muscle fibertype gene expression. American Journal of Physiology -Cell Physiology 279, C915-C924.

Tajbakhsh S and Buckingham M 2000. The birth of muscle progenitor cells in the mouse: spatiotemporal considerations. Current Topics in Developmental Biology 228, 225-268.

Tesseraud S, Metayer S, Duchene S, Bigot K, Grizard J and Dupont J 2007. Regulation of protein metabolism by insulin: value of different approaches and animal models. Domestic Animal Endocrinology (in press).

Thomas M, Langley B, Berry C, Sharma M, Kirk S, Bass J and Kambadur R 2000. Myostatin, a negative regulator of muscle growth, functions by inhibiting myoblast proliferation. Journal of Biological Chemistry 275, 40235-40243.

Ueki N and Hayman MJ 2003. Direct interaction of Ski with either Smad3 or Smad4 is necessary and sufficient for Ski-mediated repression of transforming growth factor- $\beta$ signaling. Journal of Biological Chemistry 278, 32489-32492.

Van Rooij E, Doevendans PA, Crijns HJGM, Heeneman S, Lips DJ, Van Bilsen M, Williams RS, Olson EN, Bassel-Duby R, Rothermel BA, De Windt L, et al, 2004. MCIP1 overexpression suppresses left ventricular remodeling and sustains cardiac function after myocardial infarction. Circulation Research 94, 18e-26.

Vollenweider P 2003. Insulin resistant states and insulin signaling. Clinical Chemistry and Laboratory Medicine 41, 1107-1119.

Vyas DR, Spangenburg EE, Abraha TW, Childs TE and Booth FW 2002. GSK$3 \beta$ negatively regulates skeletal myotube hypertrophy. American Journal of Physiology -Cell Physiology 283, C545-C551.

Wang Y-X, Lee C-H, Tiep S, Yu RT, Ham J, Kang H and Evans RM 2003. Peroxisome-proliferator-activated receptor $\delta$ activates fat metabolism to prevent obesity. Cell 113, 159-170.

Weiss A and Leinwand LA 1996. The mammalian myosin heavy chain gene family. Annual Review of Cell and Developmental Biology 12, 417-439.

Wigmore PMC and Stickland NC 1983. Muscle development in large and small pig fetuses. Journal of Anatomy 2, 235-245.

Wilson EM, Hsieh MM and Rotwein P 2003. Autocrine growth factor signaling by insulin-like growth factor-II mediates MyoD-stimulated myocyte maturation. Journal of Biological Chemistry 278, 41109-41113.

Wolfe RR 2006. The underappreciated role of muscle in health and disease. American Journal of Clinical Nutrition 84, 475-482.
Wood JD, Enser M, Fisher AV, Nute GR, Richardson RI and Sheard PR 1999. Manipulating meat quality and composition. Proceedings of the Nutrition Society 58, 363-370.

Wood JD, Nute GR, Richardson RI, Whittington FM, Southwood O, Plastow G, Mansbridge R, da Costa N and Chang KC 2004. Effects of breed, diet and muscle on fat deposition and eating quality in pigs. Meat Science 67, 651-667.

Wood JD, Richardson RI, Nute GR, Fisher AV, Campo MM, Kasapidou E, Sheard PR and Enser M 2003. Effects of fatty acids on meat quality: a review. Meat Science 66, 21-32.

Wu G, Bazer FW, Wallace JM and Spencer TE 2006. Intrauterine growth retardation: implications for the animal sciences. Journal of Animal Science 84, 2316-2337.

Wu H, Naya FJ, McKinsey TA, Mercer B, Shelton JM, Chin ER, Simard AR, Michel RN, Bassel-Duby R, Olson EN and Williams RS 2000a. MEF2 responds to multiple calcium-regulated signals in the control of skeletal muscle fiber type. EMBO Journal 19, 1963-1973.

Wu H, Rothermel B, Kanatous S, Rosenberg P, Naya FJ, Shelton M, Hutcheson KA, DiMaio M, Olson EN, Bassel-Duby R and Williams RS 2001. Activation of MEF2 by muscle activity is mediated through a calcineurin-dependent pathway. EMBO Journal 20, 6414-6423.

Wu YZ, Crumley RL and Caiozzo VJ 2000b. Are hybrid fibers a common motif of canine laryngeal muscles?: single-fiber analyses of myosin heavy-chain isoform composition. Archives of Otolaryngology - Head and Neck Surgery 126, 865-873.

Wu Z, Woodring PJ, Bhakta KS, Tamura K, Wen F, Feramisco JR, Karin M, Wang JYJ and Puri PP 2000c. p38 and extracellular signal-regulated kinases regulate the myogenic program at multiple steps. Molecular and Cellular Biology 20, 3951-3964.

Yang J, Rothermel B, Vega RB, Frey N, McKinsey TA, Olson EN, Bassel-Duby R and Williams RS 2000. Independent signals control expression of the calcineurin inhibitory proteins MCIP1 and MCIP2 in striated muscles. Circulation Research 87, 61-68.

Yang SY and Goldspink G 2002. Different roles of the IGF-I Ec peptide (MGF) and mature IGF-I in myoblast proliferation and differentiation. FEBS Letters $522,156-160$.

Yimlamai T, Dodd SL, Borst SE and Park S 2005. Clenbuterol induces musclespecific attenuation of atrophy through effects on the ubiquitin-proteasome pathway. Journal of Applied Physiology 99, 71-80.

Yu YH, Liu BH, Mersmann HJ and Ding ST 2006. Porcine peroxisome proliferator-activated receptor $\gamma$ induces transdifferentiation of myocytes into adipocytes. Journal of Animal Science 84, 2655-2665.

Zierath JR and Hawley JA 2006. Skeletal muscle fiber type: influence on contractile and metabolic properties. PLoS Biology 2, 1523-1527.

Zimmermann S and Moelling K 1999. Phosphorylation and regulation of Raf by Akt (protein kinase B). Science 286, 1741-1744.

Zorzano A, Kaliman P, Guma A and Palacin M 2003. Intracellular signals involved in the effects of insulin-like growth factors and neuregulins on myofibre formation. Cellular Signalling 15, 141-149. 